\title{
Simulation of Tropical Cyclones Using Spectral Bin Microphysics
}

\author{
Alexander Khain and Barry Lynn \\ Department of Atmospheric Sciences, \\ The Hebrew University of Jerusalem, \\ Israel
}

\section{Introduction}

\subsection{Bulk-parameterization and spectral bin microphysics}

Latent heat release is the main energetic source of tropical cyclones (TCs). The intensity of TCs depends on the magnitude of latent heat release (convective heating), as well as on its vertical distribution, and spatial pattern. The latent heat release in clouds depends on the rates of microphysical processes such as: condensational growth/evaporation of droplets, deposition/sublimation of ice, riming and freezing/melting. These microphysical processes are closely related to cloud dynamical properties such as vertical velocity, cloud top height, etc.Droplets and the majority of ice crystals arise on aerosol particles (AP) playing the role of cloud condensational nuclei $(\mathrm{CCN})$ and ice nuclei (IN), respectively. It is well known that droplet size distributions (DSD) and precipitation formation depend on the concentration and size of CCN. Therefore, the convective heating in TCs should depend on the properties of AP in the environment of TCs.

Most equations describing microphysical processes, including those responsible for cloudaerosol interaction are well known in Cloud Physics. Advanced microphysical schemes are needed in order to describe microphysical processes adequately and to properly take into account microphysical factors (such as aerosols). Yet, advanced microphysical schemes are not generally used in tropical cyclone forecasting models. Rather, until 2006 the current operational TC forecast model developed at the Geophysical Fluid Dynamics Laboratory used large scale convective parameterizations (Kurihara 1973 and a simplified version of the Arakawa and Shubert scheme). Since 2006 this model used a simplified ArakawaSchubert scheme for cumulus parameterization and a simplified version of the Ferrier bulkparameterization for large-scale condensation in cases when supersaturation in grid points is reached (Bender et al 2007). Both schemes are insensitive to aerosols.

The development of one and two-moment bulk parameterization schemes and their application in mesoscale models was an important step toward the improvement in the description of convective processes and precipitation in numerical models. These schemes were implemented in mesoscale and/or forecast modles such as the Penn State/NCAR Mesoscale Modeling System Version 5 (MM5) (Dudhia et al., 1997), RAMS (Pielke et al, 1992) and the Weather Research Forecast Model (Skamarock et al, 2005), the operational numerical weather prediction model of the German Weather Service (COSMO) (that is combined with an extended version of the 2-moment bulk scheme by Seifert and Beheng 
2006), etc. These models use an a priori prescription of the shape of size distribution functions (SDF) of different cloud hydrometeors (such as cloud droplets, rain drops, graupel, aggregates) in the form of exponential Marshal-Palmer distributions or gamma distributions. This reduces the system of equations that describes cloud microphysics to a relatively small number of equations for integral quantities such as mass contents (one moment schemes) and mass contents and number concentrations (two moment schemes). The comparatively small number of prognostic equations makes the schemes computationally efficient, so they are widely utilized in simulating different cloud-related phenomena such as supercell storms, squall lines, etc. These schemes were recently used for simulation of TCs (e.g., Zhang et al, 2007; Fierro et al, 2007).

Note that SDF of different hydrometeors in clouds significantly vary with space and time during cloud evolution. Size distributions of most hydrometeors are bi-modal or multimodal. Sometimes the SDF are very narrow and do not contain small and large hydrometeors. The complicated shape of the SDF is the result of many highly nonlinear microphysical processes. As a result, in many cases SDF cannot be approximated by gamma or exponential distributions. To some extent, the gamma or exponential size distributions can be considered as those obtained by the spatial and time averaging of SDF in clouds. In particular spatial points and particular time instances, the shape of SDF can dramatically deviate from the prescribed shapes. Microphysical phenomena (e.g. precipitation triggering, cloud glaciation, etc.) are determined by local SDF, and not by averaged ones. The utilization of a priori assumption of gamma or exponential distributions with a prescribed parameters is only one of limitations of the bulk-parameterization schemes. Microphysical processes are described in most of these schemes using simple semi-empirical relationships with solutions may substantially differ from the solutions of the microphysical equations based on the first principles.

The second approach to simulate microphysical processes is the utilization of spectral bin microphysics (SBM), in which a system of kinetic equations for size distributions of particles of different classes is solved. Each size distribution function is described using several tens of mass (size) bins. The SBM schemes use the microphysical equations based on the first principles trying to avoid utilization of semi-empirical relationships. A brief comparison of the methods used in the SBM and bulk-parameterization approaches is presented in Table 1. One-moment bulk schemes do not use any information about aerosols. Two-moment schemes use some information about aerosols in parameterization of droplet nucleation. The potential source of aerosols is considered to be infinitely large. As a rule, the bulk schemes do not include the transport of aerosols. In contrast, SBM describes aerosol effects on cloud microphysics and dynamics taking into account the aerosol budget, i.e. a limited source of aerosol particles. A special aerosol size distribution is used to take into account the transport and sinks of AP of different size.

As a rule, bulk-parameterization schemes do not solve the equation for diffusion growth of drops. Instead, the saturation adjustment assumption is used according to which all supersaturated water vapor is transferred into cloud water mass, so that the final supersaturation is assumed equal to zero. The assumption of saturation adjustment is not valid in atmospheric clouds, especially in maritime clouds, where supersaturation is high and may exceed $5-10 \%$. The immediate transformation of supersaturated vapor into liquid may lead to overestimation of the rate of latent heat release. In contrast, the SBM schemes solve equation for diffusional droplet growth/evaporation that takes into account effects of aerosols of differential growth rate of droplets. 
BULK vs BIN

\begin{tabular}{|c|c|c|}
\hline Properties & BULK -parameterization & Spectral bin microphysics \\
\hline $\begin{array}{l}\text { Main } \\
\text { principle }\end{array}$ & $\begin{array}{l}\text { The shape of size distributions } \\
\text { is prescribed a priori }\end{array}$ & $\begin{array}{l}\text { Model solves system of kinetic equations } \\
\text { for size distributions }\end{array}$ \\
\hline Aerosols & $\begin{array}{l}\text { No aerosol budget, } \\
\text { No aerosol transport, no } \\
\text { distribution of aerosols with size }\end{array}$ & $\begin{array}{l}\text { Aerosol budget, size distribution of } \mathrm{CCN} \text {, } \\
\text { transport of aerosols, cloud-aerosol } \\
\text { interaction }\end{array}$ \\
\hline $\begin{array}{l}\text { Condensatio } \\
\text { n/evaporation } \\
\text { of drops: }\end{array}$ & $\begin{array}{l}\text { No equation for condensational } \\
\text { growth ; All supersaturation } \\
\text { immediately transfers to cloud } \\
\text { water }\end{array}$ & $\begin{array}{l}r \frac{d r}{d t}=\frac{1}{F}\left(S-\frac{A}{r}+\frac{B r_{N}^{3}}{r^{3}-r_{N}^{3}}\right) \\
\text { In maritime clouds } \mathrm{S}>10 \%\end{array}$ \\
\hline Colli & $\begin{array}{l}\text { Simplified equations like: } \\
\qquad \frac{d q_{\text {rain }}}{d t}=k\left(q_{\text {cloud }}-q_{\text {thresh }}\right)\end{array}$ & $\begin{array}{l}\text { Stochastic collision equation } \\
\frac{\partial f(m, t)}{\partial t}=\int_{0}^{m / 2} f\left(m^{\prime}, t\right) K\left(m^{\prime}, m-m^{\prime}\right) f\left(m-m^{\prime}, t\right) d m^{\prime}-\int_{0}^{\infty} f(m, t) K\left(m, m^{\prime}\right) f\left(m^{\prime}, t\right) d m^{\prime},\end{array}$ \\
\hline Sedimentation & $\begin{array}{l}\text { The same fall velocity for } \\
\text { particles belonging to the same } \\
\text { class }\end{array}$ & $\begin{array}{l}\text { Differential fall velocity depending on } \\
\text { particle size, form and air density }\end{array}$ \\
\hline $\begin{array}{l}\text { Melting } \\
\text { freezing }\end{array}$ & $\begin{array}{l}\text { Assumption that the shape of } \\
\text { size distributions remains } \\
\text { during the highly non-linear } \\
\text { processes }\end{array}$ & $\begin{array}{l}\text { the shape of size distributions changes } \\
\text { during these non-linear processes }\end{array}$ \\
\hline
\end{tabular}

Table 1. Comparison between bulk-parameterization and spectral bin microphysics

While SBM solves the stochastic equation of collisions to calculate the rate of production of precipitating particles, bulk-parameterization schemes use semi-empirical relationships for autoconversion rates often with hidden or internal assumptions about the production rates of precipitating particles.

Most microphysical processes (advection, settling, collisions, freezing, melting, etc.) are highly non-linear. For instance, the rate of freezing is proportional to drop mass, so that large raindrops should freeze first, small ice particles should melt first. The shape of size distributions changes substantially through these processes. SBM describes these processes explicitly by solving the kinetic equations for size distributions. Bulk-parameterization schemes assume that the size distributions remain gamma or exponential. Therefore, it is not surprising that the SBM and bulk schemes lead to different results (different precipitation, convective heating, cloud type, etc).

Several versions of SBM have been developed at the Department of Atmospheric Sciences of the Hebrew University of Jerusalem. The more detailed version (Khain et al 2008a) contains a larger number of mass bins, higher number of size distribution functions, more accurate description of the processes of big hail formation, melting, etc. This version is used in a 2-D Hebrew University Cloud Model (HUCM) for simulation of single clouds, cloud systems, squall lines.

Another version with a simplified description of some microphysical processes is used in 3D simulations of supercell storms and TCs (e.g. Lynn et al, 2005a,b; Khain et al 2010) .

In case bulk-parameterizations are used, a simulation of any case study begins with the procedure of tuning of the model parameters. The necessity of the tuning indicates actually 
that clouds arising under different conditions have different microphysical structure and obey different precipitation efficiency. The purpose of the tuning is to adjust the results to observations in particular case study. A substantial advantage of the SBM model is that it does not require any tuning of the scheme parameters and can be successfully used without any tuning of parameters for simulation of deep maritime convection (Khain et al, 2004, 2008b), continental clouds including pyro-clouds (Khain et al, 2008a), squall lines (Lynn et al, 2005a,b; Tao et al 2007; Li et al 2009a,b; Khain et al, 2009), supercell storms (Khain and Lynn 2009) and arctic stratiform clouds (Fan et al, 2009). All comparisons indicate a substantial advantage of SBM over bulk-parameterization schemes as regards to simulation of precipitation and observed cloud properties. Note, however, that the standard SBM schemes require $\sim 50$ times more computer time than standard one-moment bulkparameterization schemes, which hinders their wide application in operative forecast models, and in particular, in TC forecast models.

Below we describe results of simulations of TC using the SBM.

\subsection{Aerosol effects on maritime convection}

As suggested above, it is preferred to use SBM schemes when studying aerosol effects on cloud microphysics and dynamics. During the past decade it was found that aerosols (including anthropogenic ones) substantially affect cloud microphysics, and consequently the rate of latent heat release, the dynamics and the precipitation (see, overviews by Levin and Cotton, 2009; Khain 2009; Rosenfeld et al, 2008). In particular, it was found that small aerosols invigorate tropical convection increasing vertical velocities and cloud top heights of deep convective clouds (Khain et al, 2004, 2005, 2008a; Koren et al 2005; Lynn et al, 2005a,b, Wang 2005, Lee et al 2008 ; Khain 2009). Thus, aerosols affect cloud microphysics and dynamics.

An example of aerosol effects on cloud microphysics as follows with simulations using the HUCM is shown in Figure 1 showing fields of cloud drop and graupel mass contents in deep convective clouds developing in maritime atmospheres under thermodynamic conditions typical of hurricane season. The differences between simulations are only in the concentration of CCN. The left panels show the fields obtained in case of low CCN concentration typical of clean maritime air $\left(100 \mathrm{~cm}^{-3}\right)$. The right panels show the fields in case of high CCN concentration $\left(1500 \mathrm{~cm}^{-3}\right)$. Such concentration is reached when there is penetration of continental aerosols into TC clouds when TCs approach land. One can see that the increase in the $\mathrm{CCN}$ concentration dramatically increases the amount of supercooled water aloft, as well as the graupel mass. The physical mechanism of such effect is as follows. An increase in concentration of small aerosols increases droplet concentration and decreases droplet size. The net effect is the decrease in the collision rate, a delay in raindrop formation. As a result, small droplets ascend in cloud updrafts and continue growing by condensation. This leads to an increase in supercooled water content, which intensifies ice-water collisions accompanied by freezing of liquid water. Both processes are accompanied by extra latent heat release leading to an increase in cloud updrafts and sometimes to an increase in cloud top height (Khain 2009). Therefore, clouds developing in polluted air are as a rule stronger and deeper than those developing in clean air. An increase in the mass of condensate means the increase in latent heat release and in the updraft velocity. This effect indicates an aerosol-induced invigoration of convection. 


\section{Low (maritime) aerosol concentration}
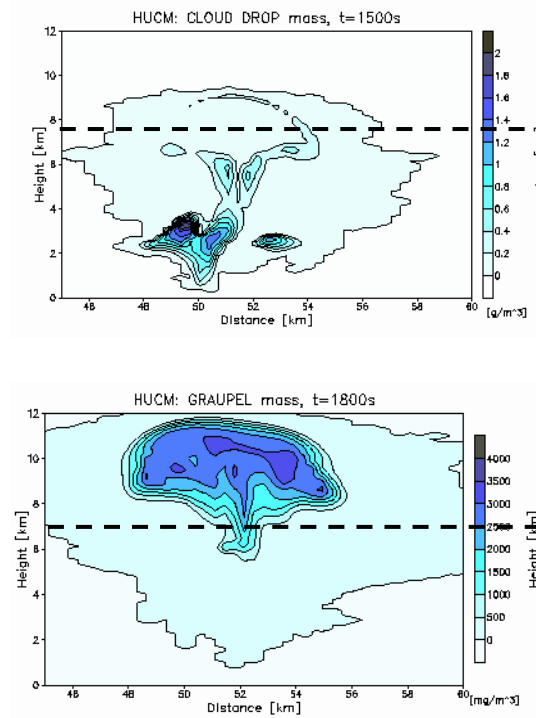

High (continental) aerosol concentration
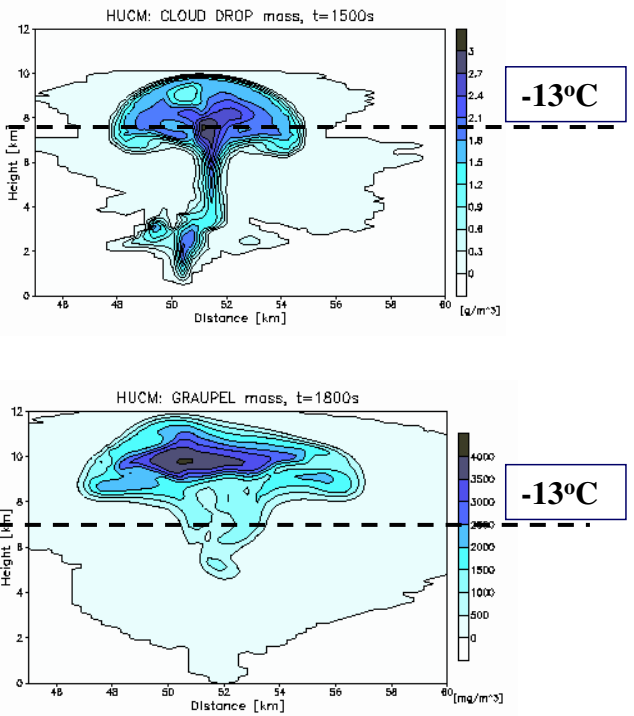

Fig. 1. Liquid water (upper row) and graupel mass content (bottom) fields in simulation of deep martitime clouds using the HUCM. Left panels show the microstructure of cloud developing in clean atmosphere. Right panels show the microstructure of the same cloud but developing in polluted air (after Khain et al 2008b).

Note that an increase in the concentration of $\mathrm{CCN}$ creates conditions favorable for lightning. It is known that charge separation in clouds takes place during ice crystals-graupel collisions under the presence of supercooled water. As seen in Fig. 1, an increase in the CCN concentration increased both the supercooled liquid water and graupel content at temperatures colder than $-13^{\circ} \mathrm{C}$. The numerical results show actually, that small CCN are able to transform typical maritime clouds into thunderstorms.

When a TC approaches the land, it imbibes huge masses of continental aerosols into its circulation. This should lead to intensification of convective clouds at the TC periphery. Tropical depressions in the eastern Atlantic Ocean often develop in polluted air (Saharan dust). Therefore, one can expect that aerosols affect the intensity of land falling TCs, as well as TC genesis via their effects on convective clouds.

Indirect evidence of aerosol effects on TC intensity can be derived from enhanced lightning at the periphery of landfalling TCs (Molinari et al 1994; Khain et al 2008b). Khain et al (2008b) simulated the evolution of hurricane Katrina (August 2005) during its movement in the Gulf of Mexico using a two nested grid Weather Research Model (WRF, NCAR version) with the Thompson et al. (2004) one-moment bulk-parameterization. Effects of continental aerosols were simulated by preventing warm rain by shutting off the drop-drop collisions only at the hurricane periphery. A similar approach was used by Rosenfeld et al (2007). Khain et al (2008b) conclude that continental aerosols that penetrated the TC periphery caused enhanced lightning flashes in the areas of penetration. It was also shown that aerosols, invigorating clouds at $250-300 \mathrm{~km}$ from the TC center, decrease the convection intensity in the TC eyewall leading to some TC weakening. Similar results were reported by 
Rosenfeld et al (2007), who proposed a method of TC mitigation by seeding of clouds at the TC periphery near their cloud base with small aerosol particles of $0.05 \mu \mathrm{m}$ to $0.1 \mu \mathrm{m}$ in radius. Simulations of the evolution of an idealized TC using Regional Atmospheric Meteorological System (RAMS) (Zhang et al, 2007) supported the conclusion that aerosols (for instance, Saharan dust) can substantially affect the intensity of TCs.

Below we present results of simulation of hurricane Katrina over the Gulf of Mexico as well as tropical depression Debbie using the WRF with a spectral bin microphysics scheme.

\section{Simulation of land-falling TC}

\subsection{Model and experimental design}

\subsubsection{Spectral bin microphysics scheme}

The SBM scheme implemented into the WRF (Skamarock et al., 2005, version 3) has been described by Khain et al (2004) and Lynn et al (2007). The original scheme is based on solving the kinetic equation system for the size distributions of seven classes of hydrometeors: water drops, three types of crystals (columnar-, plate- and branch-type), aggregates (snow), graupel and hail. Each hydrometeor class is described by a size distribution function defined on mass (size) grid containing 33 doubling bins. The minimum particle mass corresponds to that of the $2 \mu \mathrm{m}$ radius droplet. Aerosol particles are also described by a size distribution function containing 33 size bins. The size distributions are calculated in the course of the model integration. Using the values of supersaturation, the critical size of aerosol particles to be activated to drops is calculated. Aerosol particles exceeding the critical size are activated and the corresponding mass bins in the aerosol size distribution become empty. The SBM also takes into account possible droplet nucleation during dry air entrainment through the lateral cloud boundaries. An efficient and accurate method of solving the stochastic kinetic equation for collisions (Bott, 1998) was extended to a system of stochastic kinetic equations calculating water-ice and ice-ice collisions. The collision kernels for each pair of particles are calculated using accurate superposition method (Pinsky et al, 2001, Khain et al 2001) and used in the form of lookup tables. The ice nuclei activation is described using an empirical expression suggested by Meyers et al. (1992) and applying a semi-lagrangian approach (Khain et al 2000) to allow the utilization of the proposed diagnostic formulas in a time dependent framework. Secondary ice generation is described according to Hallett and Mossop (1974). The rate of drop freezing follows the observations of immersion nuclei by Vali (1994), and homogeneous freezing according to Pruppacher (1995). Breakup of raindrops is described following Khain et al (2004).

Since the treatment of 8 size distributions requires significant computer time, a Fast-SBM has been developed in which all ice crystals and snow (aggregates) are calculated on one mass grid (one distribution function). The ice particles with sizes below $150 \mu m$ are assumed to be crystals, while the larger ones are assigned to aggregates (snow). Similarly, high-density particles (graupel and hail) are also combined into one size distribution (graupel). As a result, the number of size distributions decreases from 8 to 4 (aerosols, water drops, low density ice, high density ice). Note that Fast-SBM keeps the main advantages of SBM: a kinetic equation system is solved using the non-parameterized basic equations, particles of each size have their own settling velocity, particles depending on their mass have different densities, etc. The test simulations showed that Fast-SBM requires less than $20 \%$ of the time of the full SBM, which makes it possible to use the Fast-SBM on standard PC-clusters. The comparison of results obtained by the Exact and Fast SBM in simulation of 
tropical cloud systems ( Khain et al 2009) shows that the Fast SBM produces microphysical and dynamical structure as well as accumulated rain at the surface quite similar to those simulated with Exact SBM.

\subsubsection{Experimental design}

WRF-SBM simulations were used to study possible aerosol effects on the evolution of Hurricane Katrina (August 2005) in the Gulf of Mexico during three days (beginning with 27 August $00 \mathrm{z}$ ) prior to landfall (on about $12 \mathrm{z} 29$ August). A two nested gridded WRF (version 3.01) was used, and the nest moved using a cyclone-following algorithm. The resolution of the finest and the outer grid was $3 \mathrm{~km}$ and $9 \mathrm{~km}$, respectively. The number of the vertical levels was 31, with the distances between the levels increasing with the height. The SBM is applied at the finest grid of $400 \times 400 \mathrm{~km}$ sizes. The initial fields were taken from the Global Forecast System Reanalysis data. The lateral boundary conditions were updated every six hours using the same data source. The Gulf of Mexico surface water temperatures were initialized on 27 August $00 \mathrm{z}$, and were not updated during the experiments. According to the reanalysis data the SST taken along the TC track reached its maximum near the shore (the place of the TC landfall).

Cloud droplets arise on aerosol particles (AP) playing the role of Cloud Condensational nuclei $(\mathrm{CCN}$ ). The initial (at $\mathrm{t}=0$ ) $\mathrm{CCN}$ size distribution is calculated using the empirical dependence of CCN $N_{c c n}$ concentration on supersaturation with respect to water $S_{w}$ (in \%)

$$
N_{c c n}=N_{o} S_{w}^{k}
$$

as described by Khain et al (2000). $N_{o}$ and $k$ are the measured constants for determining the $\mathrm{AP}$ concentration and shape of the AP size distribution. At $t>0$ the the equation for the size distribution of non-activated AP is solved. The initial AP concentration was assumed constant within the lowest $2 \mathrm{~km}$ layer and decreased exponentially with height with characteristic scale of $2 \mathrm{~km}$. Aerosols were transported over the entire computational area similarly to other scalars like the mixing ratio.

To investigate aerosol effects on microphysics and the dynamics of TCs, two simulations were carried out: a) in the first "MAR" simulation $N_{o}$ was set equal to $100 \mathrm{~cm}^{3}$, typical of a maritime atmosphere over the whole computational area b) in the second, semi-continental MAR_CON case the initial CCN concentration over the land $N_{o}$ was set equal to $1500 \mathrm{~cm}^{3}$, typical of continents under not very polluted conditions. Initially, over the sea $N_{o}$ was set equal to $100 \mathrm{~cm}^{3}$ in all simulations. In all simulations the slope parameter $k$ was set equal to 0.5. When TCs enter the Gulf of Mexico, their circulation transports aerosols from the land to sea, so that some continental aerosols penetrate clouds within TCs and affect their microphysics and dynamics. In all simulations the maximum size of dry AP is equal to $2 \mu \mathrm{m}$, which gave rise to droplets of radius $8 \mu \mathrm{m}$ at cloud base. No ultra giant CCNs (with diameters exceeding $4 \mu \mathrm{m}$ ) that could arise at high winds as a result of spray formation were assumed in the simulations.

\subsection{Results of simulations}

Figure 2 shows the time dependence of minimum pressure in all numerical simulations and in TC Katrina. One can see that the modeled TC has lower intensity during the first $\sim 50 \mathrm{~h}$ of 
simulations as compared to that of the observed minimum pressure in Katrina. Note in this connection that the WRF initialization used was not a TC forecast initial condition, so that no specific adjustment procedures were used to adopt the TC structure derived from the crude resolution $(100 \mathrm{~km})$ reanalysis data to the intensity of the real TC at $\mathrm{t}=0(27 \mathrm{Aug} 00 \mathrm{z})$. Hence, some relaxation period was required to get the model TC intensity close to the observed one. Yet, the accurate prediction of the Katrina's intensity was not the primary purpose of the study. The main purpose of the simulations was to compare the TC intensity and structure in the simulations with and without aerosol effects on the TC clouds in a strong hurricane, which is able to ingest aerosols from the continent. Figure 2 shows that the TC in the "MAR_CON run turned out substantially weaker, so that at the time instances when the TC reached its maximum intensity the minimum pressure in its center was about $\sim 16 \mathrm{mb}$ higher than in the MAR run. Note that lower (as compared to observed) intensity of the model TC leads likely to an underestimation of aerosol effects, because a weaker TC ingests lower AP amounts into the TC circulation.

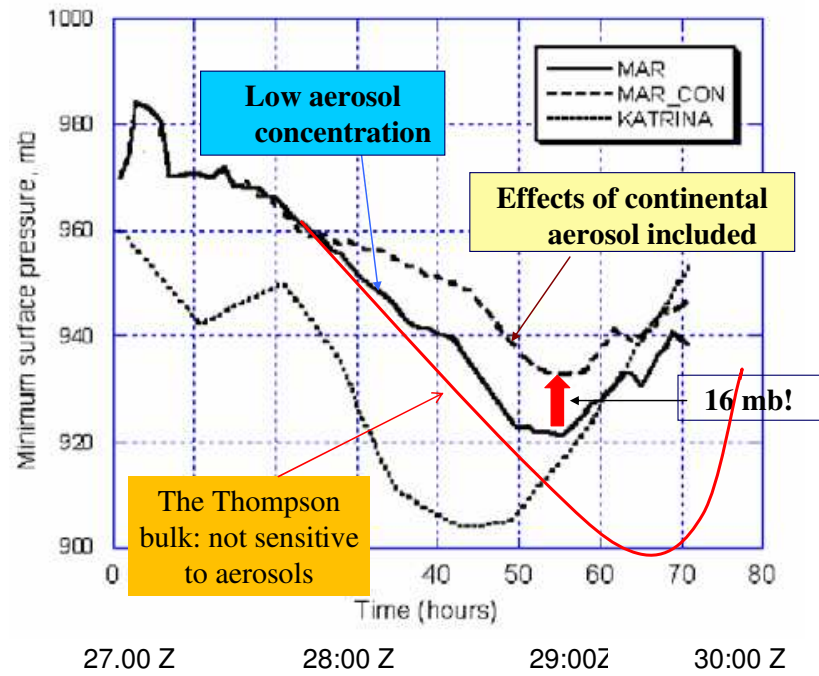

Fig. 2. Time dependence of minimum pressure in numerical experiments and hurricane Katrina (August 2005)

Note that SBM predicts correctly the TC weakening well before landfall. At the same time the bulk-parameterization schemes (for instance, the Thompson scheme) predicts the maximum TC intensity just during landfall (which does not agree with the observations). In the analysis of the aerosol fields we addressed two main questions. The first one was: whether a significant aerosol concentration can enter the TC periphery when it is located at comparatively large distance from coastal line, and second, whether aerosols can penetrate the TC eye. (Note that aerosol fields simulated in the MAR run (not shown) indicate very uniform distribution of AP concentration (which is very low) because the AP concentration over land was assumed equal to that over the sea.)

Figure 3 shows the fields of the AP concentration maximum in MAR_CON run at August 28th, at $23 \mathrm{z}$ (left) and at August 29th, at $9 \mathrm{z}$ (right) on the fine grid. The analysis of Figures 3 shows that: a) the AP concentration at the TC periphery approach concentrations similar to 
those over the continent; b) Over a significant area the aerosol concentration decreases while approaching the TC center partially because of the activation of aerosols to cloud droplets; and c) aerosols can penetrate the TC eyewall clouds along comparatively narrow streams.
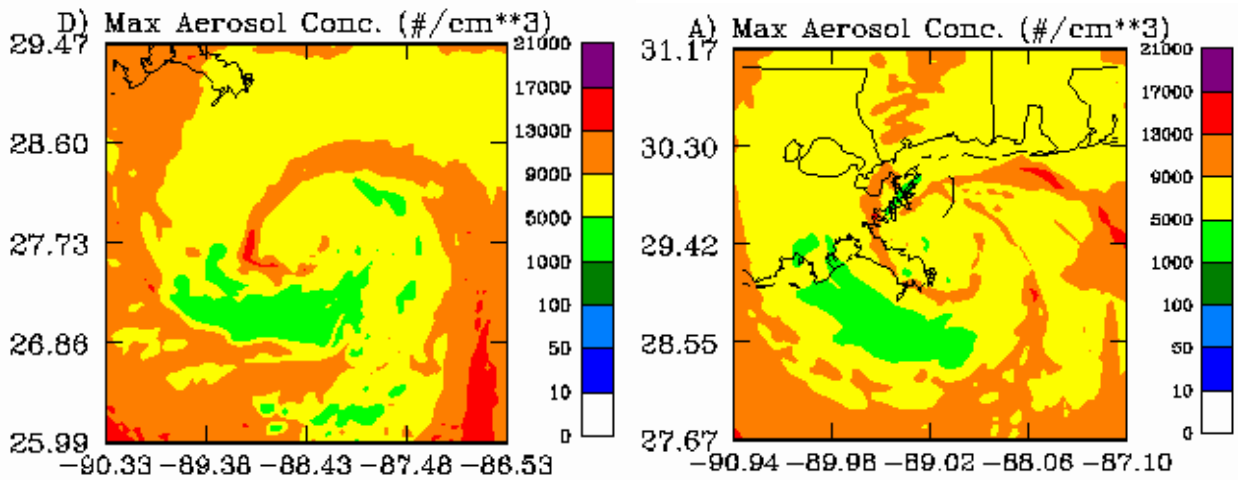

Fig. 3. Fields of maximum AP concentration in MAR_CON simulation at August 28th, at 23z (left) and at August 29th, at $9 \mathrm{z}$ (right) on the fine grid.

\section{August 28th \\ $22 z$}
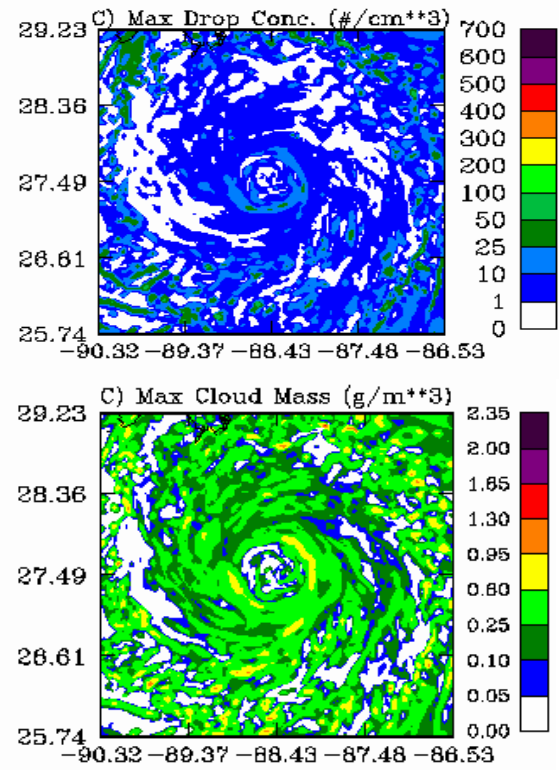

\section{EFFECTS OF CONTINENTAL AEROSOLS}

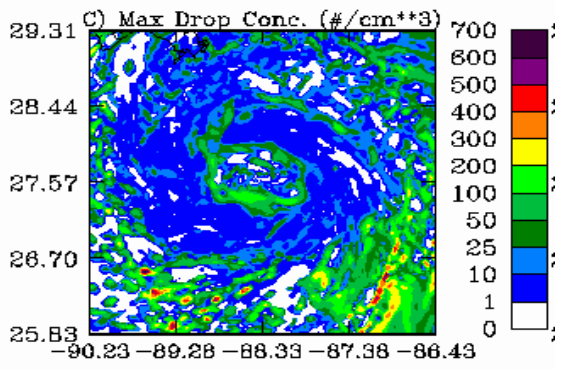

C) Max Cloud Mass (g/m**3)

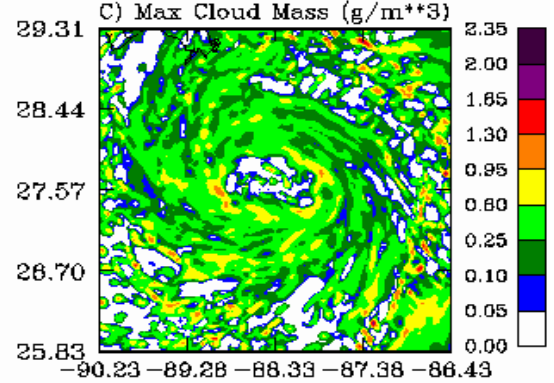

Fig. 4. Fields of the maximum droplet concentrations (upper low) and cloud droplet content (CWC) in simulations MAR (left) and MAR-CON (right) at August 28th 22z at the fine grid. 
Figure 4 compares the fields of the column-maximum droplet concentrations (upper row) and cloud water mass content (CWC) (clouds with radii below $40 \mu \mathrm{m}$ ) in clouds in simulations MAR (left) and MAR-CON (right) at August $28^{\text {th }} 22 \mathrm{z}$ on the fine grid (46h, Figure 2). One can see that in the MAR run droplet concentration does not exceed 50$100 \mathrm{~cm}^{3}$, which is a typical droplet concentration in clouds arising in clean maritime air. Zones of maximum droplet concentration in the MAR run at the TC periphery indicate zones of higher vertical velocities in rain bands. In MAR-CON, the penetration of continental aerosols led to an increase in droplet concentration at the TC periphery in the zone of high aerosol concentration, as well as in the eyewall. In the MAR-CON run the maximum droplet concentration reached $500 \mathrm{~cm}^{3}$ (especially high concentrations are at TC periphery), which is substantially higher than those in typical maritime clouds. An increase in droplet concentration within the eyewall in the MAR-CON run indicated that aerosols penetrated to the TC eyewall in the simulations.

The aerosol-induced changes in warm microphysics resulted in corresponding changes in ice microphysics. The penetration of larger amount of drops above the freezing level led to an increase graupel and snow (aggregates) contents at TC periphery (Figure 5). Note that convective invigoration of clouds at the TC periphery weakens the updrafts in the eyewall, which immediately resulted in the decrease and even disappearance of graupel and snow in the eyewall. Extra latent heat release caused by droplet condensation and freezing at the
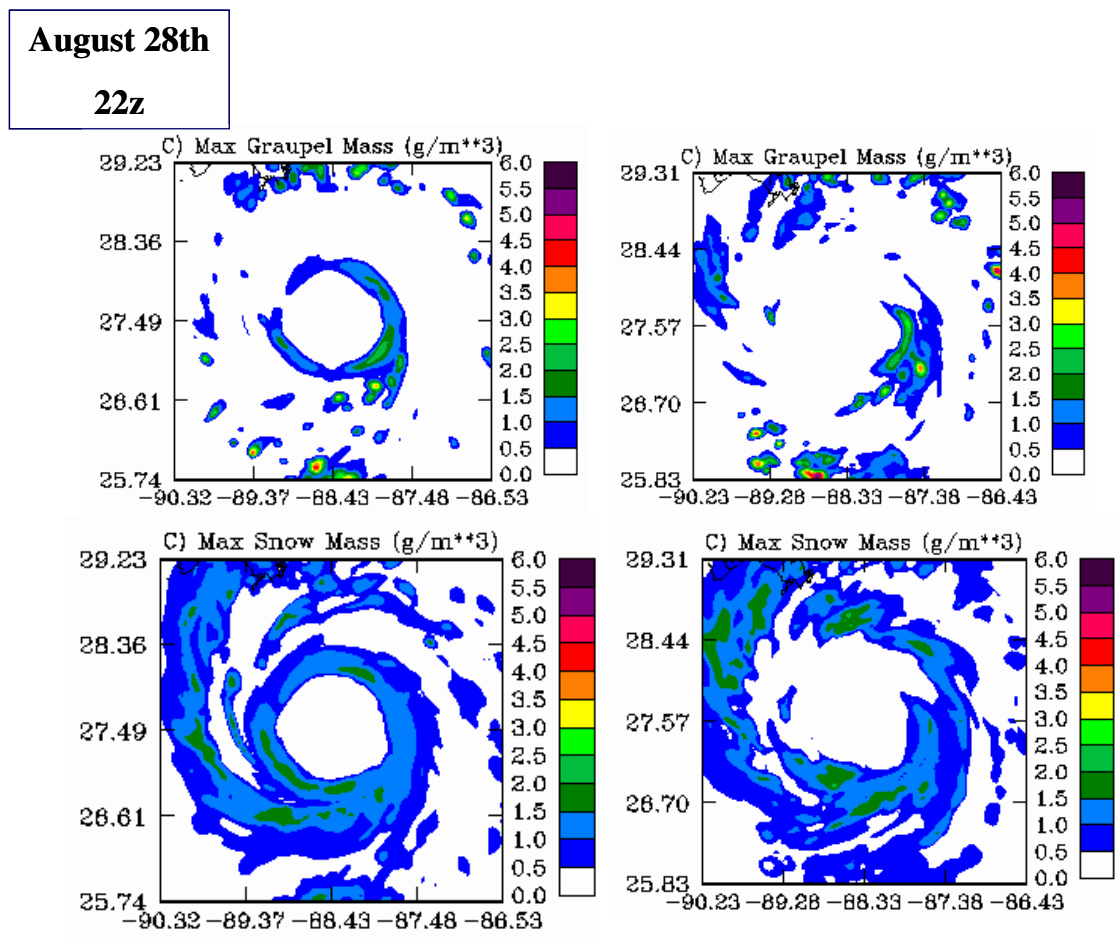

Fig. 5. The same as in Figure 3, but for fields of graupel (upper row) and snow (lower row) contents. 
periphery causesd an increase in vertical updrafts velocities and cloud top height (not shown). The values of maximum vertical velocities exceeded $10 \mathrm{~m} / \mathrm{s}$ which are rare for maritime TC clouds (Jorgensen et al, 1985). Such high velocities are required to form lightning. An increase in cloud top height within polluted air was observed from satellites (Koren et al, 2005) and simulated in many recent studies dedicated to aerosol effects on cloud dynamics (see review by Khain 2009). As it was discussed above, Khain et al (2008b) suggested that the evolution of lightning within TCs approaching land results from the ingestion of continental aerosols iinto the TC periphery. The present study strongly supports this finding.

For instance, Figure 6 presents the fields of Lightning Potential Index (LPI) at 28 Aug. $20 \mathrm{z}$,

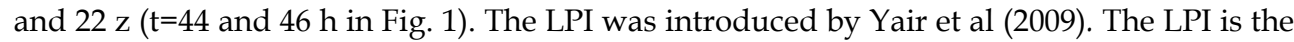
volume integral of the total mass flux of ice and liquid water within the "charging zone" $(0$ to $-20^{\circ} \mathrm{C}$ ) of the cloud. The LPI has the same meaning as the lightning probability parameter introduced by Khain et al (2008b). Fig. 6 also shows lightning in Katrina (2005) at two different time instances (Shao et al, 2005). The squares show the location of the fine grid approximately corresponding to these time instances. One can see that while in the MAR run the LPI is the highest in the eyewall all the time. Note that simulations of lightning in TC using bulk-parameterization scheme (Fierro et al 2007) (in which aerosol effects were not taken into account) also indicate that lightning was concentrated in the TC central area independently on the stage of TC evolution.
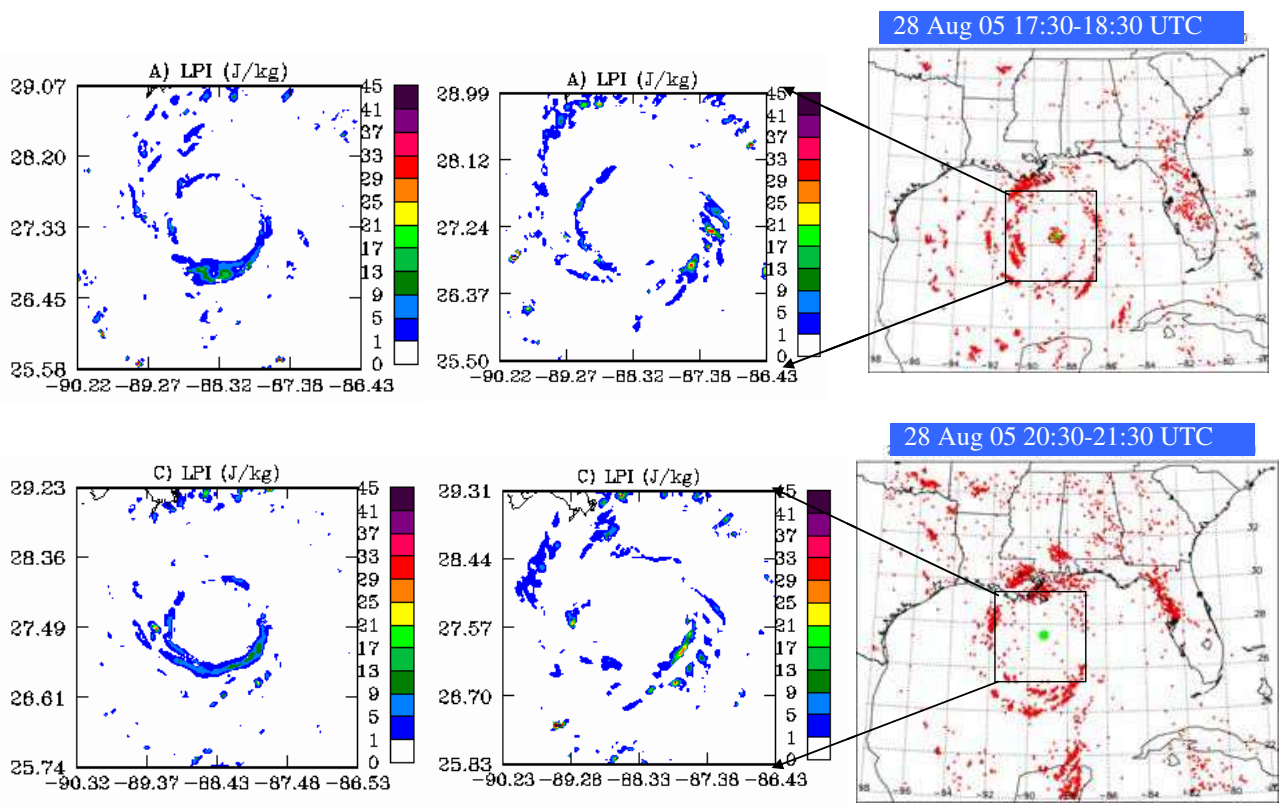

Fig. 6. The fields of Lightning Potential Index (LPI) calculated in MAR and MAR-CON runs at 28 Aug. $20 \mathrm{z}$, and $22 \mathrm{z}$. The lightning in Katrina (2005) is also presented (after Shao et al, 2005). Zones of lightning are marked by red dots; the TC eye is marked green. The square shows the location of the fine grid corresponding to these time instances (after Khain et al 2010) 
Figure 6 shows the time instance of the dissipation of the internal lightning ring in the course of intensification of convection and lightning at the TC periphery. One can see that the disappearance of lightning in the eyewall in MAR-CON run agrees well with the behavior of lightning in Katrina. The disappearance of lightning in the eyewall in the MARCON takes place about 5-6 hours before the TC weakening.

Figure 7 shows the fields of maximum wind speed 28 Aug. $21 \mathrm{z}$ (upper panels), and $22 \mathrm{z}$ in runs MAR and MAR_CON. One can see a significant decrease in the maximum wind speed up to $15 \mathrm{~m} / \mathrm{s}$, i.e. by $20-25 \%$. This decrease is substantially stronger than it was reported by Khain et al (2008b). One of the reasons is that Khain et al (2008b) used the bulkparameterization scheme that is not sensitive to aerosols, as well as the fact that an artificial approach to parameterize aerosol effects by warm rain preventing was performed within the frame of this scheme.
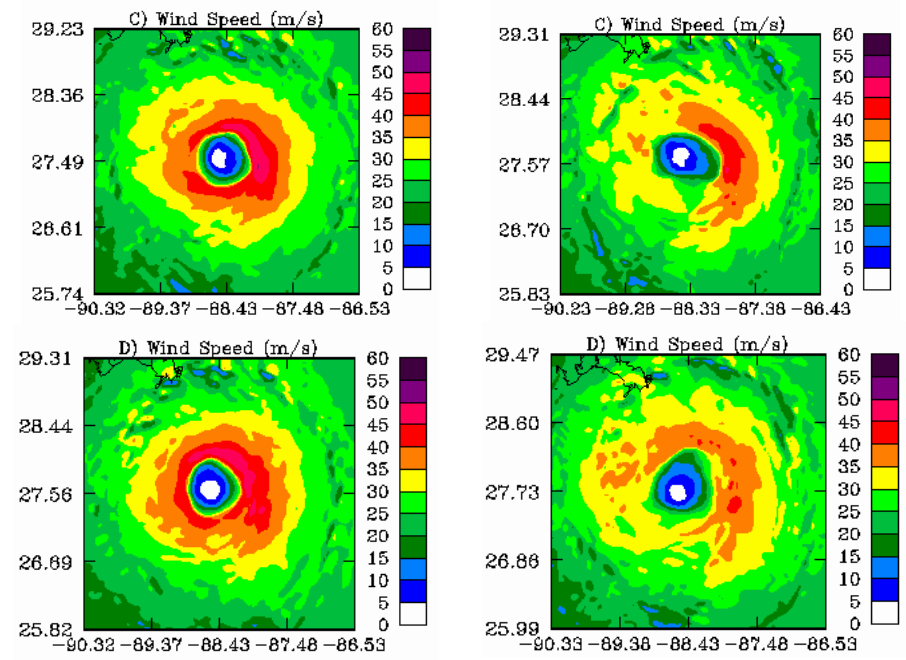

Fig. 7. The fields of maximum wind speed 28 Aug. $21 \mathrm{z}$ (upper panels), and $22 \mathrm{z}$. in runs MAR (left) and MAR_CON (right).

\subsection{Discussion}

For the first time, TC evolution was calculated using explicit spectral bin microphysics (SBM). Simulations with grid resolution of $3 \mathrm{~km}$ were made with the WRF-SBM. The evolution of Katrina was simulated during 72 hours beginning after it had just bypassed Florida to 12 hours after landfall. In these simulations the effects of continental aerosols ingested into the circulation of the TC on the TC structure and intensity were investigated. It is shown that continental aerosols invigorate convection (largely at the TC periphery), which leads to TC weakening. The TC weakening began $\sim 20 \mathrm{~h}$ before landfall, after the instance when the TC intensity reached its maximum. The minimum pressure increased by $\sim 16 \mathrm{mb}$, and maximum velocity decreased by about $15 \mathrm{~m} / \mathrm{s}$. The difference in the intensities remains significant even during the TC landfall. Thus, the results indicate that there is another (in addition to decrease in the surface fluxes) mechanism of weakening of TCs approaching land. This mechanism is related to the effects of continental aerosols ingested 
into the TC circulation. The mechanism of TC weakening is illustrated in Figure 8 showing the vertical cross-section of azimuthally averaged CWC in simulations MAR (left) and MAR-CON (right) at time instance when the maximum difference in the TC intensities took place.
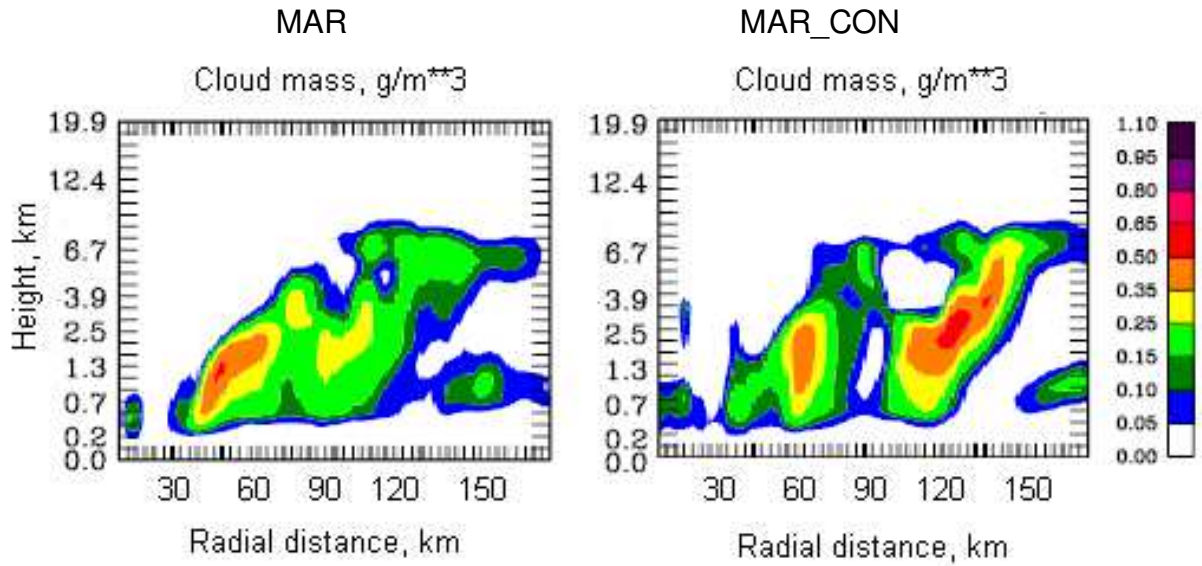

Fig. 8. The vertical cross-section of azimuthally averaged CWC in simulations MAR (left) and MAR-CON (right) at time instance when the maximum difference in the TC intensities took place.

One can see that penetration of aerosols leads to intensification of convection at the TC periphery. Thus, a competition between convection in the TC eyewall and at TC periphery occurs which leads to the weakening of the convection in the TC center. Note, that the weakening of Katrina and the collapse of the inner core occurred in both the observed storm (and in the simulated storm) even though the maximum SSTs were located near the coastal line (and no TC-ocean interaction was taken into account). The results suggest the possibility to mitigate TC intensity by seeding of clouds at the TC periphery with small aerosol particles as it was discussed by Rosenfeld et al (2007) and Khain et al (2008b).

\section{Simulation of TC genesis}

\subsection{Factors affecting TC genesis}

Despite many worthy observational and numerical modeling studies in recent decades, our understanding of the detailed physical processes associated with the early stages of tropical cyclone (TC) formation is still inadequate, and, operational forecast skill is still quite low (Gray 1998; Vizy and Cook, 2009).

General parameters affecting TC genesis such as wind shear, air humidity, SST, Coriolis force, etc., were revealed in early studies and led to deriving different expressions for seasonal potential genesis (e.g., Gray 1979; Anthes 1982; Ivanov and Khain 1983; Khainand Sutyrin, 1983; Emanuel 2005). At the same time the seasonal genesis potentials can only present some estimation of the probability of development of tropical depressions (TD) and cannot be used for the purposes of predicting the evolution of particular TDs.

Detailed analysis performed in studies by McBride (1981a,b), McBride and Zehr (1981), Erickson and Gray (1977), Zehr (1992) showed that TDs tend to develop when their vorticity 
is spatially concentrated and exceeds some critical value. Charney and Eliassen (1964) proposed the mechanism of Conditional Instability of the Second Kind (CISK) according to which convection interacts with a TC-scale vortex via the friction in the boundary layer. The friction-induced radial velocities in the boundary layer concentrate convection (and convective heating) in the central region of a TD. The convective parameterizations based on the CISK allowed developing the first models predicting TC formation. In a set of studies by Montgomery and Farrell (1993), Hendricks et al (2004), and Montgomery et al (2006), the formation of a cloud "coherent" structure in TD and the TD development is attributed to the merger of small scale vortices in conjunction with so-called vortical hot towers (VHT). Tory et al (2007) showed that the exact detail of the vortex interactions was unimportant for qualitative genesis forecast success. Instead the critical ingredients for the genesis were found to be vorticity, comparatively low vertical wind shear, and proper spatial distribution of convective forcing.

The possible sensitivity of TC intensity to the spatial distribution of latent heat release can be derived from lightning data. Lighting indicates zones with the strongest convection. The appearance and intensification of lightning in the eyewall can be a predictor of TC intensification (Lyons and Keen, 1994; Orville and Coyne 1999, Molinari et al 1999; Shao et al 2005; Demetriades and Holle, 2006; Fierro et al 2007, Price et al 2009). Rodgers et al (2000) found that the closer the lightning is to the storm center, the more likely the TC is to intensify.

An increase in computer power has allowed the investigation of TC genesis using models with a resolution of several kilometers (e.g. Wang 2002; Zhu and Zhang 2006; Frisius and Hasselbeck, 2009). Wang (2002) concluded that spiral rain bands forming at the TD periphery have a weakening effect on the tropical cyclone because they introduce lowentropy air by downdrafts into the boundary layer and hinder the boundary-layer inflow towards the eyewall. Sensitivity studies produced by Wang (2002) and Zhu and Zhang (2006) showed that the most intense tropical cyclone resulted when latent cooling processes (evaporation and melting) were switched off. More detailed investigation of spatial distribution of convective heating (latent heat release) and cooling by evaporation and melting was performed by Frisius and Hasselbeck (2009) using axi-symmetric and fully 3-D mesoscale models with bulk-parameterization of microphysical processes. In a set of sensitivity studies, they showed that whether a TD will develop or not, dramatically depends first on the spatial distribution of heating/cooling within an area of a TD. For instance, switching off drop evaporation led to a decrease in the TD eye diameter and convective inhibition outside the eyewall. As a result, the model TD rapidly developed into a TS when evaporation of water droplets or cooling caused by melting were switched off.

The spatial distribution of latent heat within a TC area may depend on the concentration of atmospheric aerosols. Many hurricanes that have reached the US coast have also been found to contain Saharan dust. The transport of Saharan dust may be so strong as to affect precipitation of Florida storms (e.g. Van Heever et al 2006).

In some studies it was shown that the penetration of Saharan dust into TDs hinders their development into tropical storms (e.g. Evan et al 2006). This effect is typically attributed to two factors: a) the penetration of warm air from Africa to the marine layer just or above the inversion, and b) to the radiative effects of dust. In the former, the penetration of Saharan dust layer also increases the stability of the atmosphere and hinders the development of convection. In this case dust plays the "passive" role of tracer of warm air. For instance, Carlson and Benjamin (1980) showed that heating rates associated with Saharan dust can be in excess of 1 
${ }^{\circ} \mathrm{C}$ per day. Using an axisymmetric TC model, Khain and Agrenich (1987) found that solar heating of dust affects TC intensity. Lau and Kim (2007) and Evan et al (2008) suppose that dust intrusions are responsible for chilling the SST in the North Atlantic. It was assumed that the outbreak of Saharan dust led via this mechanism to a decrease in TC activity. In particular, it was assumed that the excess of Sahara dust in the 2006 pre-monsoon season, as compared to 2005, contributed to the big decrease in TC activity from 2005 to 2006.

Substantiality lower attention was paid to the potential effect of aerosols (including Saharan dust) on the intensity and evolution of TD via their effect on microphysics of deep convective clouds. Some observations indicating possible aerosol effects on TD development via their influence on the cloud microphysics of TD clouds have been performed by Jenkins et al (2008) and Jenkins and Pratt (2008). Zhang et al $(2007,2009)$ investigated the effects of aerosols on the evolution of an idealized TC using RAMS with a 2-moment bulk parameterization of microphysical processes. These simulations suggested that under some conditions aerosols could lead to TC weakening.

As was shown above, continental aerosols penetrating the circulation of a TC approaching the land invigorated convection at the TC periphery and weakened its intensity in the Eye Wall leading to the weakening of the TC at landfall. These results were obtained using the WRF model with spectral bin microphysics (SBM). This microphysics allows the explicit calculation of the effects of aerosols on cloud microphysics through their effect on SDF of droplets and other hydrometeors. In this section, the evolution of TS Debbie (2006) is simulated using the WRF model with SBM.

\subsection{Model and experimental design \\ 3.2.1 Case study}

TD Debbie (AL042006) 21-26 August 2006 (Zawislak and Zipser 2010) was simulated using the WRF-SBM. Debby formed from a vigorous tropical wave that moved across the west coast of Africa on 20 August. Almost immediately after moving offshore, the wave developed convective banding and a broad closed circulation. The "best track" chart of the tropical cyclone's path is given in Figure 9. The depression initially moved westnorthwestward to the south of the subtropical ridge. Around 1200 GMT 22 August, the center of the cyclone passed about $100 \mathrm{n} \mathrm{mi}$ to the southwest of the southernmost Cape Verde Islands, bringing thunderstorms and gusty winds to the southern islands of Fogo and Brava. The depression strengthened as it moved away from the islands, becoming a tropical storm around 0000 GMT 23 August.

By 1200 GMT that day Debbie's sustained winds reached 45 Knots, and there was little or no change in strength for the next two days as the cyclone moved between west-northwest and northwest at 15-20 Knots over the open waters of the eastern Atlantic. Intensification during this period appeared to be limited by a dry and stable air mass surrounding the cyclone, along with marginal sea-surface temperatures. On 25 August, southerly shear began to increase in association with an upper-level trough, displacing the deep convection to the north of the center. Debbie started to weaken, and became a depression again around 0600 UTC 26 August (Franklin 2006).

In situ measurements in TD Debbie (Zipser et al 2009) showed the existence of strong wind shear in the 5-8 km layer. This shear inhibited convection, so that maximum updraft velocity was quite low $(\sim 5 \mathrm{~m} / \mathrm{s})$. Microphysical measurements showed the dominating contribution of graupel to ice habits. A warm core of $4-5 \mathrm{C}$ was found. The wind maximum was observed on the east side of the storm and exceeded $30 \mathrm{~m} \mathrm{~s}^{-1}$. Observations also show that 


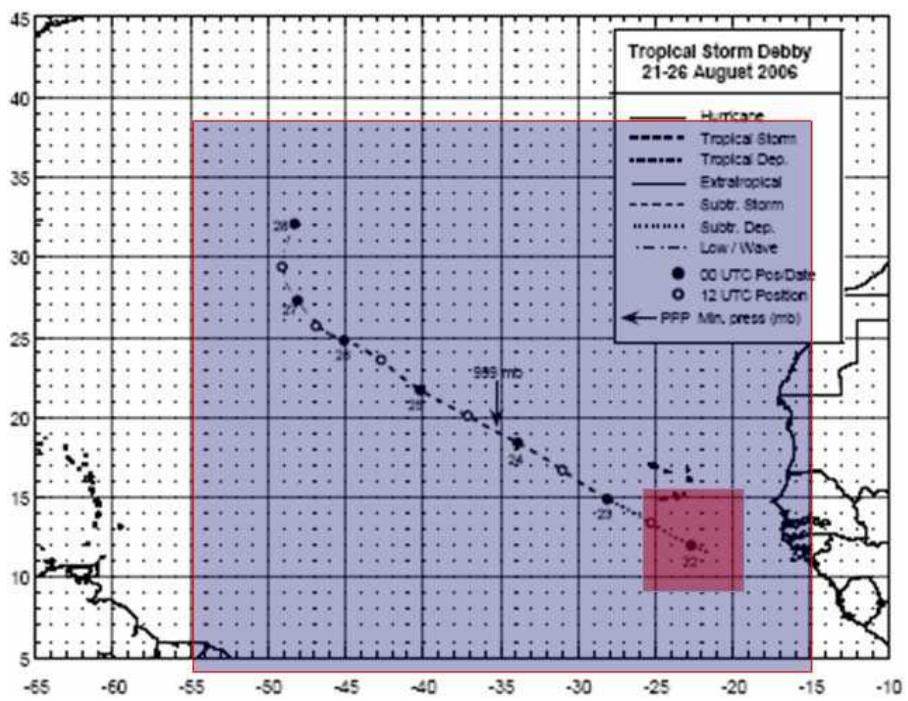

Fig. 9. Best track position for Tropical Storm Debbie, 21-26 Aug. The structure of nested grids is shown.

Debby was completely surrounded by a large Saharan Air Layer (SAL), with a significant aerosol particle layer with depth up to $\sim 5 \mathrm{~km}$. According to Zipser et al (2009) the SAL was often adjacent to Debbie's deep convective clouds, sometimes penetrating them and sometimes not. At the same time TD Debbie center region was only weakly affected by continental aerosols (Heymsfield 2010, personal communication).

\subsubsection{The simulation design}

The WRF model with SBM was similar to that used for simulation of Katrina (2005) (see Section 2). A two-nested gridded WRF (version 3.1) was used, and the nest moved using a cyclone-following algorithm. The spacing of the finest and the outer grid was $3 \mathrm{~km}$ and $9 \mathrm{~km}$, respectively. The number of the vertical levels was 31, with the distances between the levels increasing with the height. The SBM was applied at the finest grid of size $720 \times 720 \mathrm{~km}^{2}$. The inner mesh was movable and followed the height minimum at $\mathrm{z}=850 \mathrm{mb}$. The outer grid was motionless and was $3240 \times 3240 \mathrm{~km}^{2}$ with spacing of $9 \mathrm{~km}$. The bulk-parameterization of Thompson et al. (2004) was used on the outer grid. The grid structure at $t=0$ is shown in Figure 9. Integral parameters of clouds (mass contents) penetrating from the outer grid into the fine grid were recalculated into size distribution functions assuming a Marshall-Palmer size distribution as defined in the bulk-parameterization scheme. If clouds formed in the internal area penetrated the outermost grid, the size distribution functions of hydrometeors in these clouds were used to calculate mass contents used by the bulk parameterization.

The initial fields were taken from the Global Forecast System Reanalysis data. The lateral boundary conditions were updated every six hours using this data as well. The surface water temperature was initialized at 12 GMT on 20 August, and was not updated during the experiments.

Cloud droplets arise on aerosol particles (AP) playing the role of Cloud Condensational nuclei (CCN). According to observations (Zipser et al 2009) dust in the Saharan air layer 
(SAL) is slightly hygroscopic and acts as CCN. The distribution of dust had a maximum within the diameter range 0.1-0.2 $\mu \mathrm{m}$ (Zipser et al 2009). Thus, the high concentration of submicron APs may influence microphysical properties of cloud systems interacting with the SAL. The initial (at $\mathrm{t}=0$ ) CCN size distribution near the surface is calculated using the empirical dependence of concentration of activated CCN $N_{c c n}$ at supersaturation with respect to water $S_{w}$ (in \%) (eq. 1). The initial AP concentration was assumed constant within the lowest $2 \mathrm{~km}$ layer and decreased exponentially with height with a characteristic scale of $2 \mathrm{~km}$. Aerosols were transported over the entire computational area similarly to other scalars like the mixing ratio.

To investigate the possible aerosol effects on the evolution of the TD, two simulations were carried out: a) in the first simulation, $N_{o}$ was set equal to $100 \mathrm{~cm}^{-3}$ typical of maritime atmosphere over the whole computational area (hereafter, referred to as "MAR"); $b$ ) in the second, the initial CCN concentration over the land $N_{o}$ was set equal to $3000 \mathrm{~cm}^{-3}$, typical of continents under not very polluted conditions. Initially, over the sea $N_{o}$ was set equal to 100 $\mathrm{cm}^{-3}$ in all simulations. For the maritime aerosol concentrations, the slope parameter $k$ was set equal to 0.46 . It was 0.31 for the continental AP concentrations. The magnitudes of these parameters are typical of maritime and continental conditions, respectively (Pruppacher and Klett 1997). The vertical profiles of the aerosols decreased exponentially with height beyond two kilometers.

The evolution of the background fields was initially simulated for six hours to allow time for the dust to move from over the continent to over the ocean in the experiment MAR-CON. Then, weak temperature sinusoidal heating along the vertical line passing through the point of minimum geopotential at $\sim 800 \mathrm{gPa}$ was used to trigger the TS. The heating zone was moved with the TD. The heating maximum of about $8^{\circ} \mathrm{C}$ day-1 was applied during 18 hours. This magnitude of the heating is quite small: it is only a few times larger than the radiative forcing. For instance, it is much lower than that in natural clouds, where the heating reaches 100 (and more) ${ }^{\circ} \mathrm{C} \mathrm{day}^{-1}$. The physical meaning of the application of the initial heating is the same as application of bogusing techniques of implementation of initial vortex. However, the implementation of initial heating does not lead to complex processes of mutual adaptation of temperature and pressure fields. The heating does not distort substantially the asymmetric environmental flow as occurs with the implementation of axisymmetric bogus vortex. The advantage of the heating is especially significant in the case of a weak TD, where the initial vortex is very weak and highly asymmetric. Moreover, the further development or weakening of a TD may depend on the rate of asymmetry of the vortex.

The initial triggering was necessary because the crude resolution of reanalysis data does not resolve the TD scales. The heating allowed the system "to recognize" its center, but the further evolution was determined by the cloud formation within the TD, and interaction of the TD with the surroundings, etc.

In addition to simulations with SBM, similar simulations were performed using ten different bulk-parameterization schemes currently implemented into the WRF model.

\subsection{Results of simulations}

\subsubsection{Aerosol effects on microphysics and dynamical structure of simulated TD}

Figure 10 shows time dependencies of minimum pressure in Debbie and obtained in numerical simulations using SBM and 10 bulk parameterization schemes. One can see that 
both SBM simulations reproduced the observed changes in surface pressure in good agreement with observations. Toward $72 \mathrm{hr}$ of simulation time, the errors in the prediction of minimum pressure and maximum velocity were relatively low in both simulations when compared to the observed values. The simulation MAR-CON shows, however, better agreement with the observations, especially after 50 hours of simulation time. Trajectories of simulated storms coincided reasonably well with the observed trajectory in both simulations (not shown).

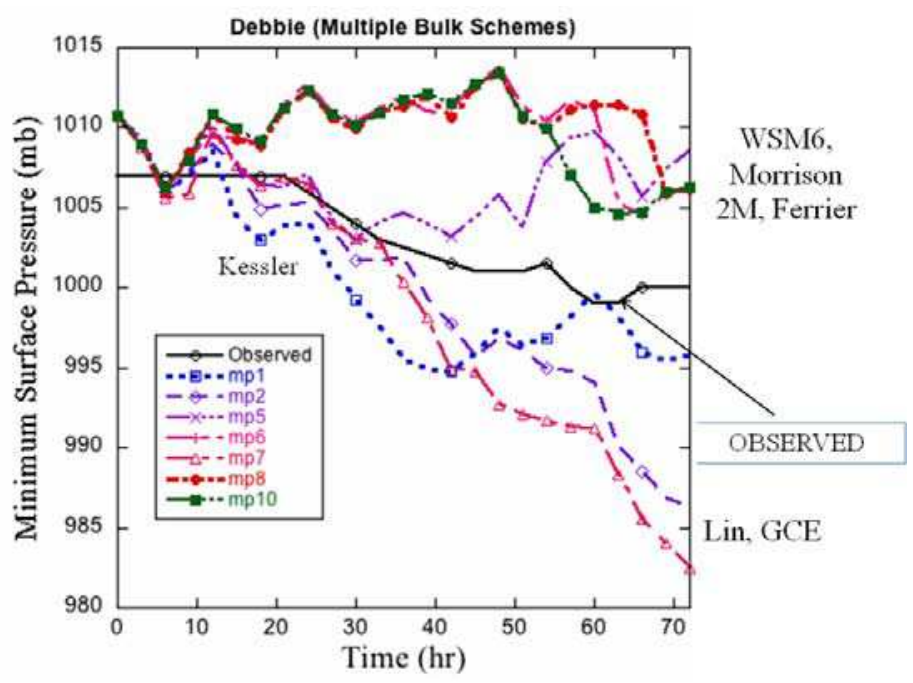

Fig. 10. Time dependencies of minimum pressure in Debbie and obtained in numerical simulations using SBM and 10 bulk parameterization schemes.

One can see that SBM reproduced well the observed evolution of the TD. While the TC intensity was reproduced better in the MAR-CON simulation, the difference between the simulated intensities in simulations with different aerosol concentrations is not large. The better reproduction of the TD microphysics in MAR-CON will be seen by comparison of different microphysical and dynamical fields.

Figure 11 shows that droplet concentration and CWC in CON_MAR are substantially larger than in MAR in agreement with both observations and simulations of maritime clouds developing in clean and polluter air (see Fig. 1). Figure 12 shows the fields of total liquid water content $(\mathrm{QC}+\mathrm{QR})$ in the north-east -south-west vertical diagonal cross -section at $\mathrm{t}=72$ $\mathrm{h}$ in MAR and MAR-CON (the line showing the cross-section is shown in Figure 11 by dashed lines. One can see the dramatic effect of APs on microphysics and structure of cloudiness. Droplets in MAR-CON are smaller than in MAR and ascend to higher levels producing supercooled rain drops at $\sim 5 \mathrm{~km}$. While in MAR, the spatial distribution of convection is more or less symmetric with respect to the TD center, it is highly asymmetric in MAR-CON. In MAR-CON droplets penetrate to higher levels and produce stronger supercooled rain that starts at height of $6-7 \mathrm{~km}$. 

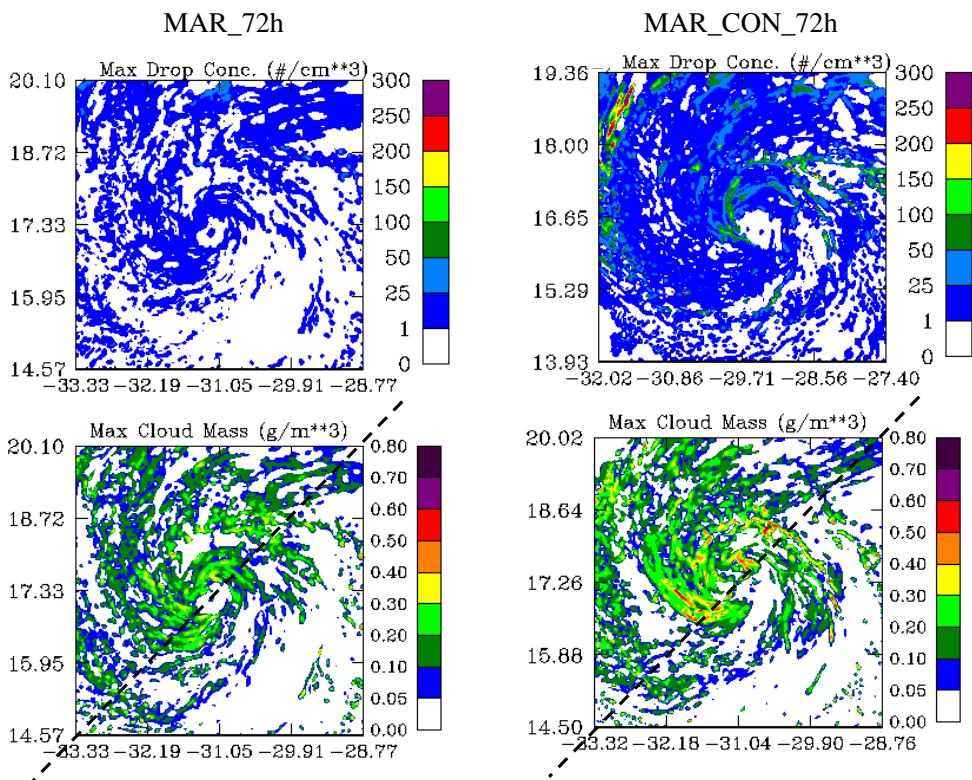

Fig. 11. Fields of maximum values of droplet concentration and cloud water content in simulations MAR (left) and MAR-CON (right) at $\mathrm{t}=72 \mathrm{~h}$.

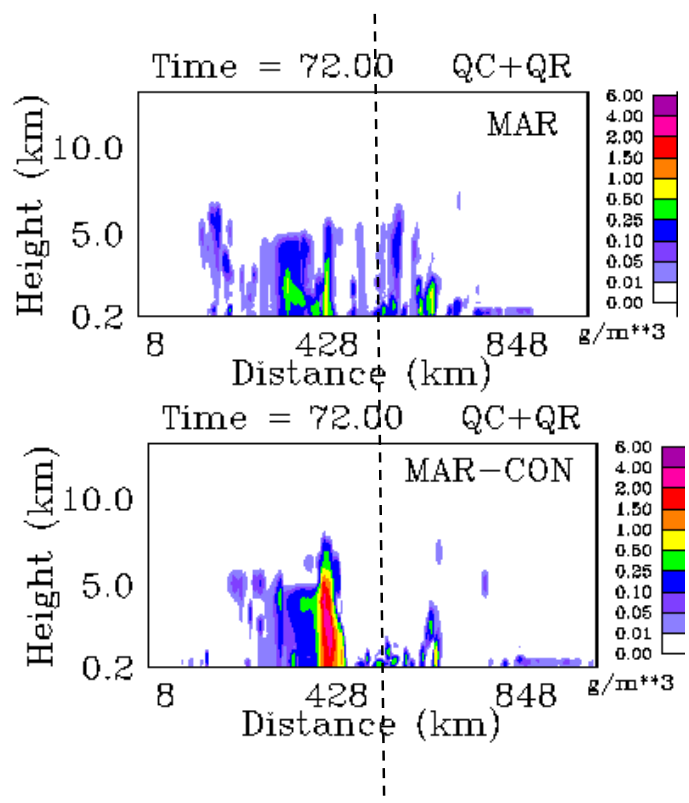

Fig. 12. Fields of total liquid water content $(\mathrm{QC}+\mathrm{QR})$ in the north-east -south-west vertical diagonal cross -section at $\mathrm{t}=72 \mathrm{~h}$ in MAR and MAR-CON (the line showing the cross-section is shown in Fig. 11 by dashed lines. 
Figure 13 shows fields depicting the maximum updrafts. Prior to the penetration of aerosols into the storm, convection was concentrated in the storm central region in both simulations (not shown). Later the differences in the $\mathrm{W}$ fields became significant: $\mathrm{W}$ are lower in MAR, but elevated values are more strongly concentrated with respect to the TS center. In MAR_CON, the vertical velocities are higher (up to $7 \mathrm{~m} / \mathrm{s}$ ), but zones with high updrafts are located more that $100 \mathrm{~km}$ from the TS center. Convection at the TC periphery is stronger in MAR-CON. A comparison of the two sets of maps reveals the aerosol-induced convection invigoration reported earlier in many observational and numerical studies (see Khain 2009 for detail) and discussed above.
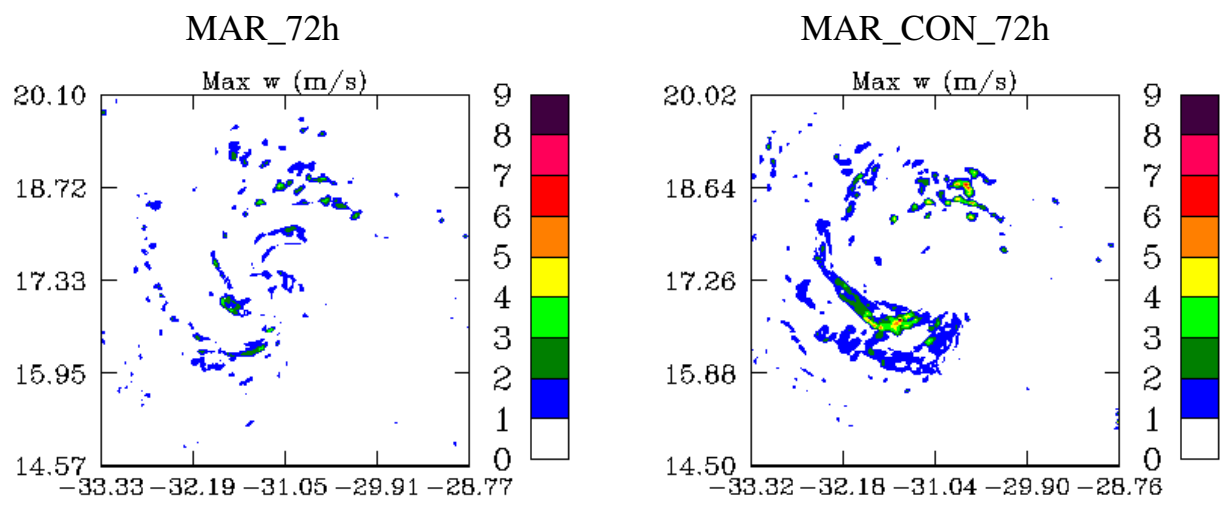

Fig. 13. Fields depicting the maximum updrafts in MAR (left) and MAR_CON (right) at $t=72 \mathrm{~h}$.

Differences in warm microphysics and updrafts of clouds in MAR and MAR-CON lead to dramatic difference in ice microphysics. Figure 14 show fields of maximum values of snow and graupel in MAR and MAR_CON at $\mathrm{t}=72 \mathrm{~h}$.

Graupel is the dominating solid hydrometeor in MAR-CON, while snow dominates in MAR. The difference in the snow and graupel contents can be attributed to the fact that in MAR-CON supercooled CWC is higher than in MAR that leads to more intense riming of snow, which converts it to graupel. In the MAR experiment there is very little supercooled water and snow does not transfer to graupel as rapidly as in MAR-CON. Again one can see that convection is stronger in the TS center in MAR, while it is stronger in MAR-CON at the TS periphery. Note that according to in-situ observations (Zipser et al 2009), graupel was dominating in Debbie, which corresponds well with the measurements of significant concentrations of AP in the surrounding cloud bands of this TC.

The microphysical and dynamical factors mentioned above lead to significant differences in the wind speed (Figure 15). Note that in MAR and MAR-CON maximum wind speed occurs to the east of the TS center which is in agreement with observations (Zipser at al 2009).

In spite of the fact that the maximum values of wind speed are close in both runs, Figure 15 indicates substantial difference in the TS wind structure. In MAR strong winds cover larger area around the TS center than in MAR-CON. At the same time zone of moderate winds covers a much larger area than that in MAR, indicating a much slower decrease of wind speed with the increase in the distance from the TS center as compared to that in MAR. Taking into account that the TC Debbie started weakening at $72 \mathrm{~h}$, results obtained in MARCON seem to be closer to observations. 

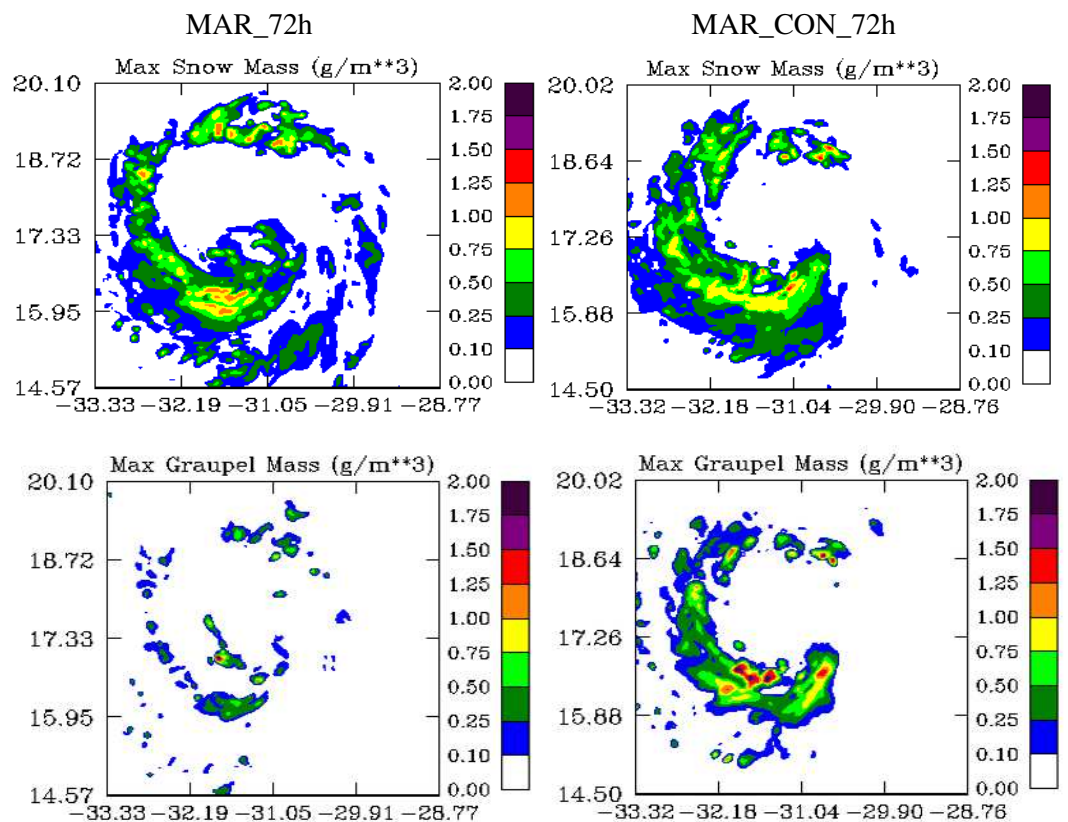

Fig. 14. Fields of maximum of snow and graupel mass contents in MAR and MAR_CON at $\mathrm{t}=72 \mathrm{~h}$.

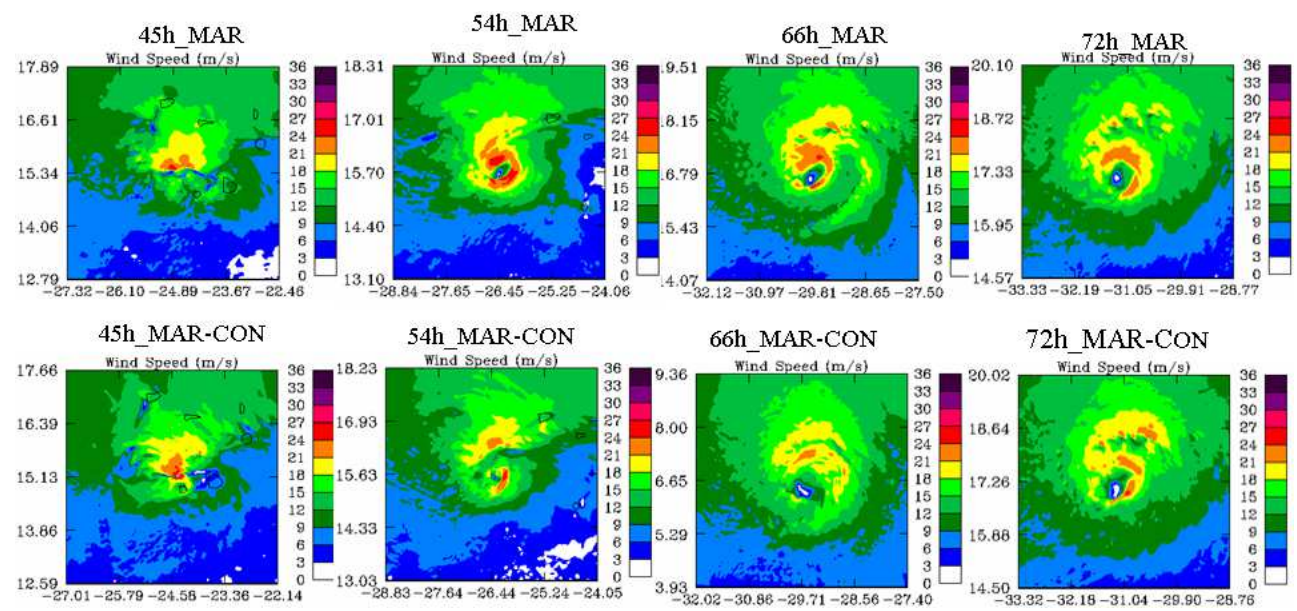

Fig. 15. Fields of the maximum wind in the simulations MAR and MAR_CON at different time instances.

The radar reflectivity calculated in the same cross-section with the observed one (Zipser et al 2009) shows that the structure of convection is substantially asymmetric with the maximum of convection within the south-east quadrant; the calculated maximum radar reflectivity of 55-60 $\mathrm{dBZ}$ is reached within the layer from 3 to $5 \mathrm{~km}$ which agrees well with the observations. 


\subsubsection{Comparison of SBM with bulk parameterization schemes}

The simulations with bulk-parameterization of convection reveal a wide range of forecasts from non-developing TDs to TCs of hurricane strength (Figure 10), but failed to reproduce the evolution of TD Debbie. Recall that all simulations were performed within the same dynamical framework and the same initial conditions. The difference between the simulations was only in the representation of convection. It is paradoxical that among all bulk-schemes, the best agreement with observations was attained using the simplest onemoment Kessler parameterization (mp1 in Figure 10) which does not include ice processes. Figure 10 stresses the importance of the utilization of correct physics to reproduce the evolution of tropical storms. The second clear conclusion is that the improvement of model resolution will not produce better results without utilization of appropriate microphysics.

Important conclusion that can be derived from Figures 2 and 10 is that in spite of the important role of aerosol effects, the difference between intensities of model TC is determined largely by different representations of physical processes in different microphysical schemes.

A more detailed comparison was performed between the results of the SBM simulations and those using two moment bulk-parameterization scheme, i.e, WDM6 with the prediction for the mixing ratios of six water species (water vapor, cloud droplets, cloud ice, snow, rain, and graupel) (Lim and Hong, 2010). This scheme is one of the most advanced bulk-schemes and predicted the evolution of TD better than most of other bulk schemes. In contrast to most other bulk schemes WDM6 predicts aerosol concentration. This allowed performing simulations with WDM6 similar to those performed with SBM. These simulations will be referred to as WDM6_MAR and WDM6_CON, respectively. Figure 16 shows time dependencies of minimum pressure and maximum wind speed in Debbie, as well as in simulations using SBM and WDM6. The TS simulated with WDM6 is weaker than Debbie. Effects of aerosols as it simulated by WDM6 turns out to be opposite to that in SBM, namely, in WDM6 the increase in the aerosol concentration leads to formation of TD of higher intensity.
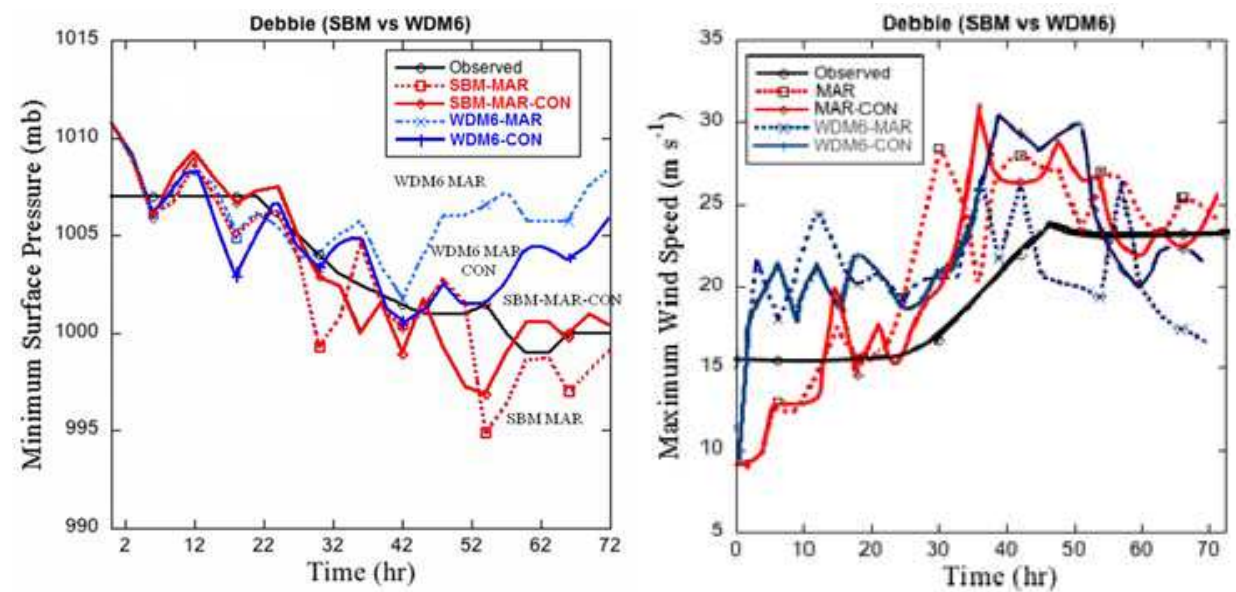

Fig. 16. Time dependencies of minimum pressure and maximum wind speed in Debbie, as well in simulations using SBM and WDM6. 
Figures 17 and 18 compare the fields of maximum of cloud and rainwater contents (RWC) in simulations with SBM and WDM6. Comparison of the CWC and RWC shows substantial differences between the fields simulated by SBM and WDM6. Intensity of TD simulated with the SBM is more sensitive to aerosols than in simulations with WDM6. In WDM6 maximum values of CWC are similar in cases of clean and polluted air. This result does not agree with those obtained in many observational and numerical studies (see Figure 1). WDM6 predicts larger maximum values of CWC and RWC than SBM. In WDM6 both CWC and RWC field have a spotted structure indicating very intense clouds. In contrast the SBM simulations show a wide range of CWC and precipitation gradations. The underestimation of low rate precipitation and overestimation of the rate of strong convective precipitation is a typical feature of the bulk schemes.

MAR, $72 \mathrm{~h}$

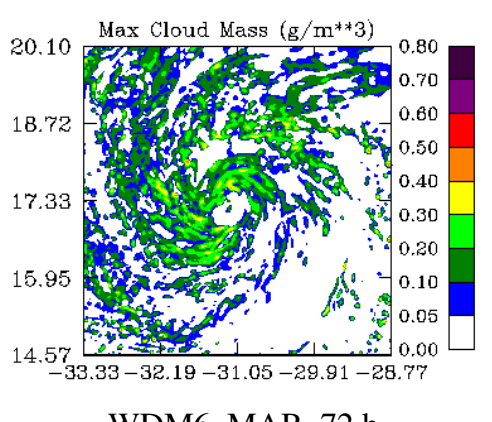

WDM6_MAR, $72 \mathrm{~h}$

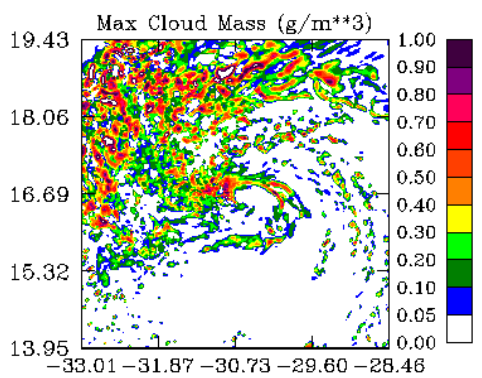

MAR_CON, $72 \mathrm{~h}$

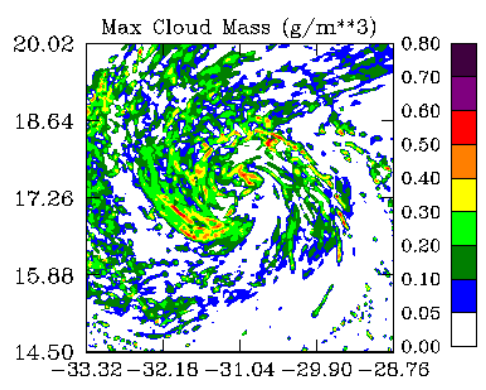

WDM6_CON, $72 \mathrm{~h}$

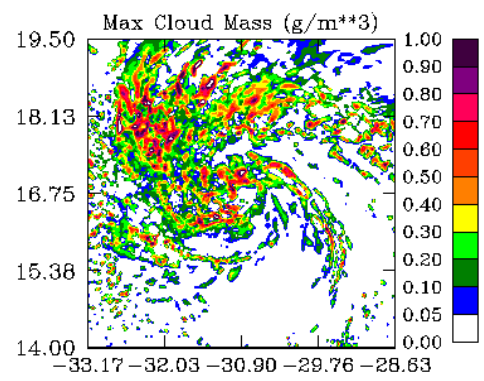

Fig. 17. Fields of the maximum of cloud water contents in simulations with SBM and WDM6 at $\mathrm{t}=72 \mathrm{~h}$.

The structure of CWC and RWC in the SBM simulations indicates the formation of TC vortex more clearly than that simulated using WDM6. 

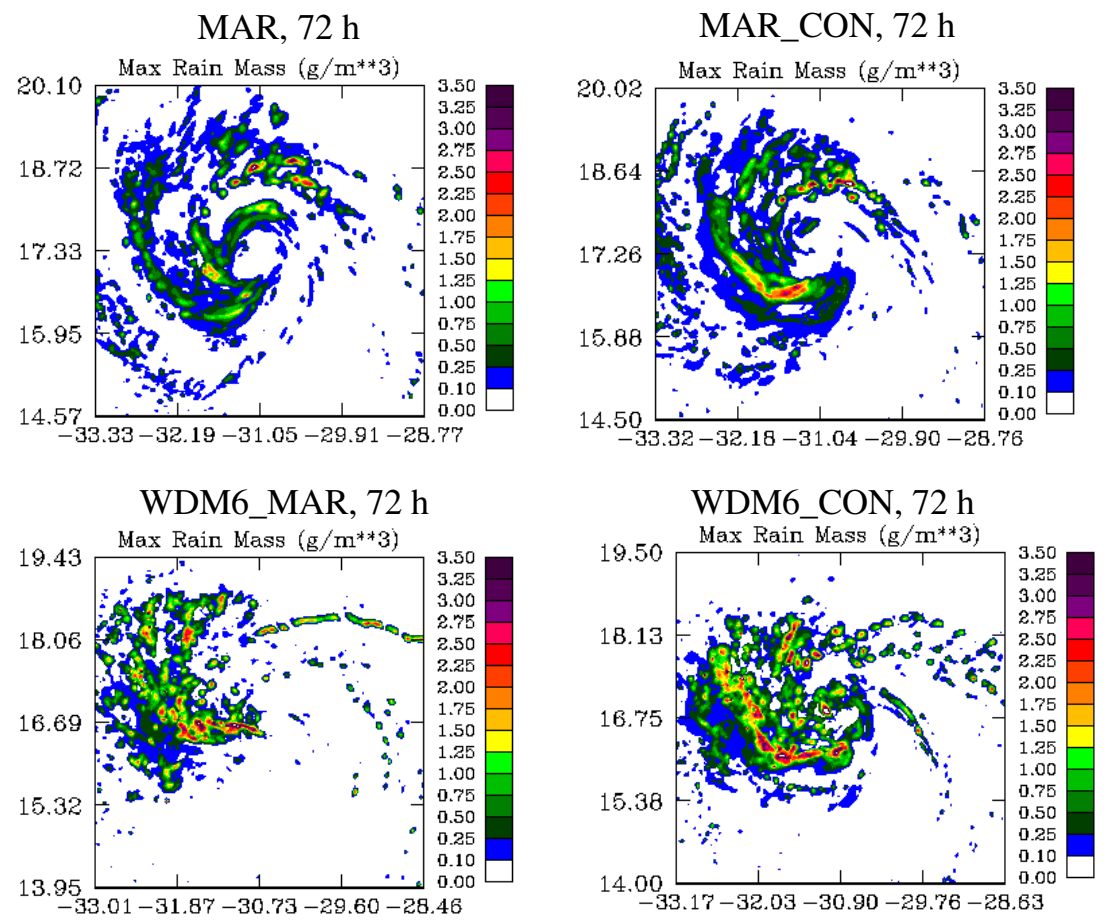

Fig. 18. Fields of the maximum of cloud water contents in simulations with SBM and WDM6 at $\mathrm{t}=72 \mathrm{~h}$.

Figure 19 shows fields of maximum snow and graupel contents in the WDM6 simulations. The difference between the fields of snow and graupel contents simulated using WDM6 and SBM is even larger than that between fields of liquid water. The maximum values of these ice hydrometeors in WDM6 are substantially lower than those simulated by SBM. Thus, WDM6 indicates stronger warm rain processes (larger CWC and RWC) and much weaker ice processes (lower values of snow and graupel contents) as compared to the SBM. Owing the intense lightning observed in Debbie (lightning is caused by ice-graupel collisions in the presence of supercooled water) the results obtained using the SBM seem to be more realistic. In the WDM6 both graupel and snow contents are larger in the polluted case. In contrast, the SBM predicts lower snow content in the polluted atmosphere. As was discussed above, smaller amounts of snow can be attributed to more intense riming in polluted clouds containing more supercooled water. Other results such as the concentration of the strongest winds in the eastern part of storm, the dominating role of graupel, low vertical velocities (below $5 \mathrm{~m} / \mathrm{s}$ ) simulated using SBM also agree with observations better than those obtained with WRM6.

As regards other bulk-parameterizations tested, the microphysical fields produced by these schemes are quite unrealistic, so no comparison is presented here. 

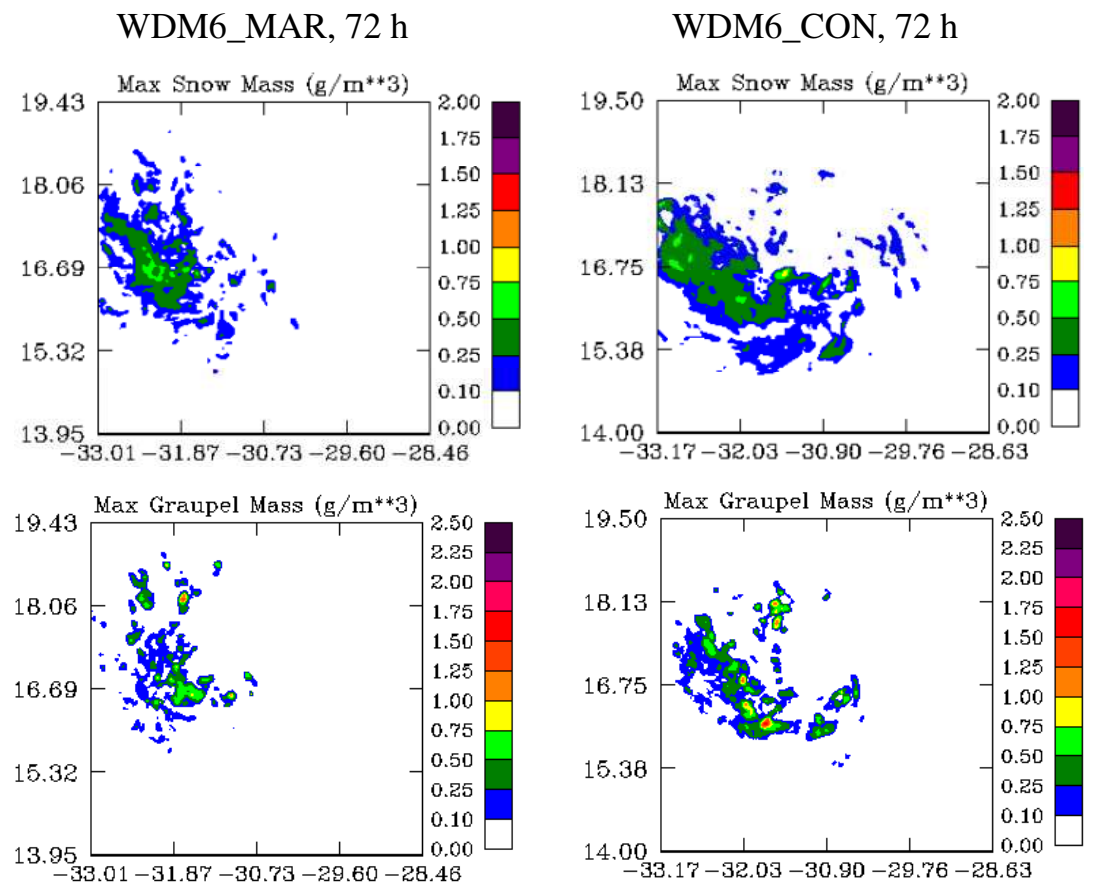

Fig. 19. Fields of maximum snow and graupel contents in the WDM6 simulations at $t=72 \mathrm{~h}$.

\section{General conclusions}

Results obtained using the first simulations of landfalling hurricanes and developing tropical depressions using spectral bin microphysics are quite encouraging. The utilization of SBM based on solving microphysical equations showed significant potential for both further investigation of physical processes in tropical cyclones and for improvement of intensity prediction skill. In all simulations the SBM reproduced the TC intensity (and intensity variations) better than the bulk-parameterization schemes. For instance, the WRF/SBM predicted the TC weakening well before landfall in agreement with observations.

According to Vizy and Cook (2009) "There is currently no parameterization accounting for the influence of the variability of aerosol forcing in the WRF model. These simulations described in this chapter show that such model does now exist. The results show an important effect of aerosols on microphysics and dynamics of TC. The effect of aerosols is strongly related to the spatial distribution of latent heat within the TC area. The aerosolinduced convective invigoration at the TC periphery leads to TC weakening. We suppose that aerosol effects are as important as TC-ocean coupling.

The WRF with spectral bin microphysics seems to be an efficient tool for the investigation of TC genesis and the role of desert dust in this process. The WRF-SBM can serve also as a benchmark model for calibration of bulk parameterization schemes. 
The current the WRF/SBM model can be improved in several aspects. In the simulations discussed, the model resolution was $3 \mathrm{~km}$, which is not high enough to resolve comparatively small clouds at the TC periphery. The use of supercomputers should allow simulations of tropical storms with even higher resolution to obtain, quite possibly, even greater sensitivity to aerosols. Other problem to solve is the optimization of the SBM to make it more computationally efficient. Implementation of detailed processes of melting, accurate description of radar signatures from partially melted particles, etc. will be the next step of the SBM improvement in the WRF.

\section{Acknowledgements}

The study was supported by the Israel Science Foundation (grant 140/07) and scientific project HAMP supported by the US Department of Homeland security (Project FY2008-0616). The authors express their deep gratitude to Dr. Dudhia, Prof. Baik and to H. Zvi Kruglyak for help in solving many computer problems.

\section{References}

Anthes, R.A. (1982). Tropical cyclones-Their evolution, structure, and effects. Monograph 41, Amer. Meteorol. Soc., 208 pp.

Bender M.; Ginis, I.; Tuleya, R.; Thomas B. and Marchok, T. (2007). The operatuional GFDL coupled hurricane-ocean prediction system and a summary of its performance. Mon. Wea. Rev. 135, 3965-3989.

Bott, A., (1998). A flux method for the numerical solution of the stochastic collection equation. J. Atmos. Sci., 55, 2284-2293.

Carlson, T,N.: and Benjamin, S.G. (1980). Radiative heating rates for Saharan dust. J. Atmos. Sci. 37, 193-213.

Charney J. G.; Eliassen A. (1964). On the growth of the hurricane depression. J. Atmos. Sci. 21: 68-75.

Demetriades N.W.S., and Holle, R.L (2006). Long-range lightning nowcasting applications for tropical cyclones. Preprints, Conf. Meteorology Application of Lightning Data, Atlanta, AMS, 9 pp.

Dudhia, J.; Gill, D.; Guo, Y.-R.; Hansen D.; Manning, K.; and Wang, W. (1997): PSU/NCAR mesoscale modeling system tutorial class notes (MM5 modeling system version 2). http://www.mmm.ucar.edu/mm5.

Emanuel K. (2005). Divine Wind, The History and Science of Hurricanes, Oxford University Press. 2005, 296pp.

Erickson, S. L.; Gray, W. M., (1977). Comparison of developing vs. non-developing tropical disturbances. Dept. of Atmos. Sci. Paper No. 274, Colo. State Univ., Ft. Collins, CO, 80523, $81 \mathrm{pp}$.

Evan, A.T. ; J.P. Dunion; J.A. Foley; Heidinger, A.K.; and Velden, C.S. (2006). New evidence for a relationship between Atlantic tropical cyclone activity and African dust outbreaks. J. Geophys. Res., 33, L19813; doi: 101029/2006GL026408.

Evan, A.T. and Coauthors, (2008). Ocean temperature forcing by aerosols across the Atlantic tropical cyclone development region. Geochem. Geophys. Geosyst., 9, Q05V04, doi: 101029/2007GC001774. 
Fan J., Ovtchinnikov, M.; Comstock, J.; McFarlane, S; and Khain, A. (2009). Modeling Arctic mixed-phase clouds and associated ice formation. J. Geophys. Res. 114, D04205, doi:10.1029/2008JD010782.

Fierro, A.O. ; Leslie, L. ; E. Mansell, Straka, J. ; MacGorman, D. and Ziegler, C. (2007). A high-resolution simulation of microphysics and electrification in an idealized hurricane-like vortex. Meteorol. Atmos. Phys. 98, 13-33, Doi: 10.1007/s00703-0060237-0.

Franklin, J.L. (2006). Tropical cyclone report: Tropical Storm Debby (AL042006) 21-26 August, 2006. National Hurricane center, 2 Nov., 2006.

Frisius, T. and Hasselbeck, T. (2009). The effect of latent cooling processes in tropical cyclone simulations, Quart. J. Roy. Meteorol. Soc. 135: 1732-1749

Gray, W. M., (1979). Hurricanes: their formations, structure and likely role in the tropical circulation. Supplement of Meteorology Over the Tropical Oceans. Published by RMS, James Glaisher House, Grenville Place, Bracknell, Berkshire, RG 12 1BX, D. B. Shaw, (ed.), 155-218.

Gray, W. M. (1998). The Formation of Tropical Cyclones, Meteorol. Atmos. Phys. 67, 37-69 Hallett, J., and S. C. Mossop, 1974: Production of secondary ice crystals during the riming process. Nature, 249, 26-28.

Hendricks, E.A, Montgomery M.T, and Davis C. A. (2004). The role of 'vortical' hot towers in the formation of tropical cyclone Diana (1984). J. Atmos. Sci. 61: 1209-1232.

Ivanov, V. N. and Khain, A. P. (1983). On parameters determining the frequency of tropical cyclone genesis. Atmospheric and Oceanic Physics, 19, 787-795.

Jenkins G. S., Pratt A.S.; and A. Heymsfield. (2008). Possible linkages between Saharan dust and tropical cyclone rain band invigoration in the eastern Atlantic during NAMMA-06, Geophys. Res. Lett. 35, L08815, doi:10.1029/2008GL034072.2008

Jenkins, G.S. and Pratt, A. (2008). Saharan dust, lightning and tropical cyclones in the eastern tropical Atlantic during NAMMA-06, Geophys. Res. Lett., 35, L 12804, doi: 10.1029/2008GL033979.

Jorgensen, D.P., and LeMone, M.A. (1989). Vertical velocity characteristics of oceanic convection. J. Atmos. Sci., 46, 621-640.

Jorgensen, D. P.; Zipser, E.J. and. LeMone, M.A. (1985). Vertical motions in intense hurricanes. J. Atmos. Sci., 42, 839-856.

Khain, A.P., and Sutyrin, G.G. (1983). Tropical cyclones and their interaction with the ocean, Gidrometeoizdat, Leningrad (St. Petersburg), 241p.

Khain, A. P. (2009). Effects of aerosols on precipitation: a review. Environ. Res. Lett. 4 (2009) 015004.

Khain, A.P. and Agrenich, E. A. (1987). Possible effect of atmospheric humidity and radiation heating of dusty air on tropical cyclone development. Proc. Institute Experim. Meteorol., 42(127), 77-80.

Khain, A. P., Ovtchinnikov, M.; Pinsky, M. ; Pokrovsky, A. and Krugliak, H. (2000). Notes on the state-of-the-art numerical modeling of cloud microphysics. Atmos. Res. 55, 159-224.

Khain A.P., Pinsky, M.B., Shapiro, M. and Pokrovsky, A. (2001). Graupel-drop collision efficiencies. J. Atmos. Sci., 58, 2571-2595.

Khain A.; Pokrovsky; A. Pinsky; M. Seifert, A. and Phillips, V. (2004) Effects of atmospheric aerosols on deep convective clouds as seen from simulations using a spectral microphysics mixed-phase cumulus cloud model Part 1: Model description. J. Atmos. Sci., 61, 2963-2982. 
Khain, A.P.; Rosenfeld D. and Pokrovsky, A. (2005). Aerosol impact on the dynamics and microphysics of convective clouds. Quart. J. Roy. Meteor. Soc., 131, 2639-2663.

Khain A.P., Benmoshe, N.; Pokrovsky, A. (2008a). Aerosol effects on microphysics and precipitation in convective clouds with a warm cloud base: an attempt of classification. J. Atmos. Sci., 65, 1721-1748.

Khain, A.; Cohen, N.; Lynn B. and Pokrovsky, A. (2008b) Possible aerosol effects on lightning activity and structure of hurricanes. J. Atmos. Sci. 65, 3652-3667.

Khain, A., and Lynn, B. (2009). Simulation of a supercell storm in clean and dirty atmosphere using weather research and forecast model with spectral bin microphysics, J. Geophys. Res., 114, D19209, doi:10.1029/2009JD011827.

Khain, A. P, Leung, L. R.; Lynn, B. and Ghan, S. (2009) Effects of aerosols on the dynamics and microphysics of squall lines simulated by spectral bin and bulk parameterization schemes. J. Geophys. Res, 114, D22203, doi:10.1029/2009JD011902

Khain, A. P.; Lynn B. and J. Dudhia (2010). Aerosol effects on intensity of landfalling hurricanes as seen from simulations with WRF model with spectral bin microphysics, J. Atmos. Sci. , 67, 365-384

Koren I., Kaufman, Y. J.; Rosenfeld, D.; Remer L. A.; Rudich, Y. (2005) Aerosol invigoration and restructuring of Atlantic convective clouds. Geophys. Res. Lett., 32, L14828, doi:10.1029/2005GL023187.

Kurihara, Y. (1973). A scheme of moist convective adjustment. Mon. Wea. Rev., 101, 547-553.

Lau, W.K.M and Kim, K.-M. (2007) How nature foiled the 2006 hurricane forecasts. EOS. Trans. AGU, 88 (9), 105-107.

Lee, S. S., L. J. Donner, V. T. J. Phillips, and Y. Ming, 2008a: The dependence of aerosol effects on clouds and precipitation on cloud-system organization, shear and stability, J. Geophys. Res., 113, D16202, doi:10.1029/2007JD009224.

Levin Z., and Cotton, W.R. (2009) Aerosol pollution impact on precipitation: A scientific Review, WMO/IUGG report, Springer, $386 \mathrm{pp}$.

Li X, Tao, W-K.; Khain, A.P.; Simpson J. and Johnson, D. E. (2009a). Sensitivity of a CloudResolving Model to Bulk and Explicit Bin Microphysical Schemes. Part I: Validation with a PRE-STORM Case. J. Atmos. Sci. 66, 3-21.

Li X, Tao, W-K.; Khain, A.P.; Simpson J. and Johnson, D. E. (2009b). Sensitivity of a CloudResolving Model to Bulk and Explicit Bin Microphysical Schemes. Part II: Cloud Microphysics and Storm Dynamics Interactions. J. Atmos. Sci. 66, 22-40.

Lim, K-S. S. and Hong, S.-Y. (2010). Development of an Effective Double-Moment Cloud Microphysics Scheme with Prognostic Cloud Condensation Nuclei (CCN) for Weather and Climate Models. Mon. Wea. Rev., 138, 1587- 1612.

Lynn B.; Khain, A. ; Dudhia, J.; Rosenfeld, D.; Pokrovsky, A. and Seifert A. (2005a). Spectral (bin) microphysics coupled with a mesoscale model (MM5). Part 1. Model description and first results. Mon. Wea. Rev. 133, 44-58.

Lynn B.; Khain, A.; Dudhia, J.; Rosenfeld, D.; Pokrovsky, A. and Seifert A. (2005b) Spectral (bin) microphysics coupled with a mesoscale model (MM5). Part 2: Simulation of a CaPe rain event with squall line Mon. Wea. Rev., 133, 59-71.

Lynn B. and Khain, A. (2007). Utilization of spectral bin microphysics and bulk parameterization schemes to simulate the cloud structure and precipitation in a mesoscale rain event. J. Geophys. Res. 112, D22205, http:/ / dx.doi.org/10.1029/2007JD008475

Lyons, W.A., and Keen, C.S. (1994). Observations of lightning in convective supercells within tropical storms and hurricanes. Mon. Wea. Rev., 122, 1897-1916. 
McBride, J. L. (1981a). Observational analysis of tropical cyclone formation, Part I: Basic description of data sets. J. Atmos. Sci., 38, 1117-1131.

McBride, J. L. (1981b). Observational analysis of tropical cyclone formation, Part III: Budget analysis. J. Atmos. Sci., 38, 1152-1166.

McBride J.L.; Zehr R. (1981). Observational analysis of tropical cyclone formation. Part II: Comparison of non-developing versus developing systems. J. Atmos. Sci. 38: 11321151.

Meyers, M. P.; DeMott, P. J. and Cotton, W. R. (1992). New primary ice-nucleation parameterizations in an explicit cloud model. J. Appl. Meteor., 31, 708-721.

Molinari J., Moore, P. K.; Idone, V.P.; Henderson R.W. and Saljoughy, A.B. (1994). Cloud-toground lightning in hurricane Andrew. J. Geophys. Res., 99, 16665-16676.

Molinari J., Moore P., and Idone, V. (1999). Convective structure of hurricanes as revealed by lightning locations, Mon. Wea. Rev., 127, 520-534

Montgomery, M. T., Farrell, B. F. (1993) Tropical cyclone formation. J. Atmos. Sci., 50, 285-310;

Montgomery M.T.; Nicholls M.E.; Cram T.A, Saunders A.B. (2006). A vortical hot tower route to tropical cyclogenesis. J. Atmos. Sci. 63: 355-386.

Orville, R.E., and Coyne, J.M. (1999). Cloud-to-ground lightning in tropical cyclones (1986-1996). Preprints, 23-rd Conf. on Hurricanes and tropical meteorology, Dallas, Amer. Meteor. Soc., 194pp.

Pielke, R. A., Cotton, W. R.; Walko,R. L.; Tremback, C. J.; Lyons, W. A.; Grasso, L. D.; Nichols M. E.; Moran, M. D.; Wesley, A.; Lee T. J. and Copeland, J. H. (1992) A comprehensive meteorological modeling system-RAMS. Meteor. Atmos. Phys., 49, 69-91.

Pinsky, M., Khain, A. P. and Shapiro, M. (2001). Collision efficiency of drops in a wide range of Reynolds numbers: Effects of pressure on spectrum evolution. J. Atmos. Sci. 58, 742-764.

Price C., Asfur M. and Yair Y. (2009). Maximum hurricane intensity precedes by increase in lightning frequency. Nature Geosceince, Letters, 6 April, doi: 10,1038/NGEO477.

Pruppacher, H. R. (1995). A new look at homogeneous ice nucleation in supercooled water drops. J. Atmos. Sci., 52, 1924-1933.

Pruppacher, H. R., and J. D. Klett (1997). Microphysics of clouds and precipitation. 2-nd edition, Oxford Press, 1997, 963p.

Rodgers E.; Weinman, J.; Pierce, H.; Olson, W. (2000). Tropical cyclone lightning distribution and its relationship to convection and intensity change. Preprints, $24^{\text {th }}$ Conf. on Hurricanes and Tropical meteorology, Ft. Lauderdale, Amer. Meteor. Soc. pp. 537541.

Rosenfeld D., Khain, A.; Lynn, B. and Woodley, W.L. (2007). Simulation of hurricane response to suppression of warm rain by sub-micron aerosols. Atmos. Chem. Phys. Discuss., 7, 5647-5674.

Rosenfeld D., Lohmann, U. Raga, G.B.; O’Dowd, C.D. ; Kulmala, M. ; Fuzzi, S. ; Reissell, A. ; Andreae, M.O. (2008). Flood or Drought: How Do Aerosols Affect Precipitation? Science, 321, 1309-1313

Seifert, A. and Beheng, K. (2006). A two-moment cloud microphysics parameterization for mixed-phase clouds. Part 1: Model description, Meteorol. Atmos. Phys. 92, 45-66.

Shao X.M., Harlin, J.; Stock, M. ; Stanley, M.; Regan, A.; Wiens, K.; Hamlin, T.; Pongratz, M.; Suszcynsky D. and Light, T. (2005) Los Alamos National Laboratory, Los Alamos, N.M, 18 October 2005, Katrina and Rita were lit up with lightning, EOS, 86, No.42, page 398-399. 
Skamarock, W.C., Klemp, J.B.; Dudhia, J.; Gill, D.O.; Barker, D.M.; Wang, W.; and Powers, J.G. (2005). A description of the Advanced Research WRF Version 2. NCAR Tech Notes-468+STR.

Tao W-K., Li X., Khain, A.; Matsui, T.; Lang, S. and J. Simpson (2007). The role of atmospheric aerosol concentration on deep convective precipitation: Cloudresolving model simulations. J. Geophys. Res. 112, D24S18, doi:10.1029/2007JD008728, 2007

Thompson, G., Rasmussen, R. R. and Manning, K. (2004) Explicit forecasts of winter precipitation using an improved bulk microphysics scheme. Part 1: Description and sensitivity analysis, Mon. Wea. Rev., 132, 519-542.

Tory K. J.; Davidson, N. E. and Montgomery, M. T. (2007) Prediction and Diagnosis of Tropical Cyclone Formation in an NWP System. Part III: Diagnosis of Developing and Nondeveloping Storms. J. Atmos. Sci., 64, 3195-3213.

Yair, Y., Lynn, B., Price, C., Kotroni, V., Lagouvardos, K., Morin, E., Mugnai, A., and Llasat, M. C., 2010: Predicting the potential for lightning activity in Mediterranean storms based on the Weather Research and Forecasting (WRF) model dynamic and microphysical fields, J. Geophys. Res., 115, D04205, doi:10.1029/2008JD010868.

Vali, G. (1994). Freezing rate due to heterogeneous nucleation. J. Atmos. Sci., 51, 1843-1856.

Van den Heever, S. C.; Carrió, G.G..; Cotton, W.R..; Demott, P. J..; Prenni, A. J. (2006). Impacts of Nucleating Aerosol on Florida Storms. Part I: Mesoscale Simulations. J. Atmos. Sci., 63, Issue 7, pp.1752-1775

Vizy E. K. and Cook, K. H. (2009). Tropical Storm Development from African Easterly Waves in the Eastern Atlantic: A Comparison of Two Successive Waves Using a Regional Model as Part of NASA AMMA 2006, J. Atmos. Sci. 66, 3313-3334.

Wang Y. (2002). An explicit simulation of tropical cyclones with a triply nested movable mesh primitive equation model: TCM3. Part II: Model refinements and sensitivity to cloud microphysics parameterization. Mon. Wea. Rev. 130: 3022-3036.

Wang C., (2005). A modeling study of the response of tropical deep convection to the increase of cloud condensational nuclei concentration: 1. Dynamics and microphysics. J. Geophys. Res., 110; D21211, doi:10.1029/2004JD005720.

Zawislak J. , and Zipser, E. J. (2010). Observations of Seven African Easterly Waves in the East Atlantic during 2006. J. Atmos. Sci., 67, 26-43.

Zehr, R. M., (1976) Tropical cyclone intensification. Dept. of Atmos. Sci. Paper No. 259, Colo. State Univ., Ft. Collins. CO, 80523, 91 pp.

Zehr, R. (1992). Tropical cyclogenesis in the western North Pacific. NOAA Technical Report NESDIS 16, 181 pp (available from NESD1S, Washington, DC or CIRA, Colo. State Univ., Ft. Collins, CO).

Zhang H., McFarquhar, G.M. Saleeby, S.M. and Cotton, W.R. (2007). Impacts of Saharan dust as CCN on the evolution of an idealized tropical cyclone. Geophys. Res. Lett., 34, L14812, doi: 10.2029/2007GL029876.

Zhang, H.; McFarquhar, G. M.; Cotton, W. R. and Deng Y. (2009), Direct and indirect impacts of Saharan dust acting as cloud condensation nuclei on tropical cyclone eyewall development, Geophys. Res. Lett., 36, L06802, doi: 10.1029/2009GL037276.

Zhu T. and Zhang D.L. (2006). Numerical simulation of hurricane Bonnie (1998). Part II: Sensitivity to varying cloud microphysical processes. J. Atmos. Sci. 63: 109-126.

Zipser, E., and co-authors. (2009). The Saharan air layer and the fate of African easterly waves: NASA's AMMA 2006 field program to study tropical cyclogenesis: NAMMA. Bull. Amer. Meteorol. Soc.1137-1156. 


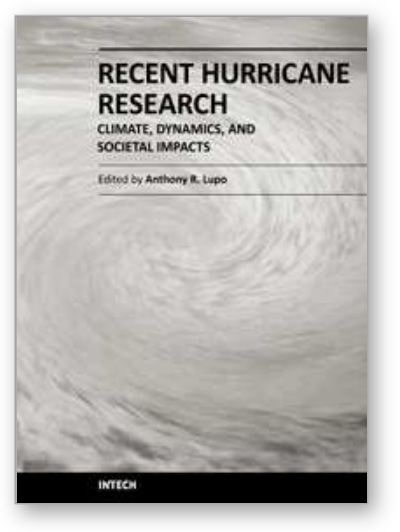

\author{
Recent Hurricane Research - Climate, Dynamics, and Societal \\ Impacts \\ Edited by Prof. Anthony Lupo
}

ISBN 978-953-307-238-8

Hard cover, 616 pages

Publisher InTech

Published online 19, April, 2011

Published in print edition April, 2011

This book represents recent research on tropical cyclones and their impact, and a wide range of topics are covered. An updated global climatology is presented, including the global occurrence of tropical cyclones and the terrestrial factors that may contribute to the variability and long-term trends in their occurrence. Research also examines long term trends in tropical cyclone occurrences and intensity as related to solar activity, while other research discusses the impact climate change may have on these storms. The dynamics and structure of tropical cyclones are studied, with traditional diagnostics employed to examine these as well as more modern approaches in examining their thermodynamics. The book aptly demonstrates how new research into short-range forecasting of tropical cyclone tracks and intensities using satellite information has led to significant improvements. In looking at societal and ecological risks, and damage assessment, authors investigate the use of technology for anticipating, and later evaluating, the amount of damage that is done to human society, watersheds, and forests by land-falling storms. The economic and ecological vulnerability of coastal regions are also studied and are supported by case studies which examine the potential hazards related to the evacuation of populated areas, including medical facilities. These studies provide decision makers with a potential basis for developing improved evacuation techniques.

\title{
How to reference
}

In order to correctly reference this scholarly work, feel free to copy and paste the following:

Alexander Khain and Barry Lynn (2011). Simulation of Tropical Cyclones Using Spectral Bin Microphysics, Recent Hurricane Research - Climate, Dynamics, and Societal Impacts, Prof. Anthony Lupo (Ed.), ISBN: 978953-307-238-8, InTech, Available from: http://www.intechopen.com/books/recent-hurricane-research-climatedynamics-and-societal-impacts/simulation-of-tropical-cyclones-using-spectral-bin-microphysics

\section{INTECH}

open science | open minds

\author{
InTech Europe \\ University Campus STeP Ri \\ Slavka Krautzeka 83/A \\ 51000 Rijeka, Croatia \\ Phone: +385 (51) 770447 \\ Fax: +385 (51) 686166 \\ www.intechopen.com
}

\author{
InTech China \\ Unit 405, Office Block, Hotel Equatorial Shanghai \\ No.65, Yan An Road (West), Shanghai, 200040, China \\ 中国上海市延安西路65号上海国际贵都大饭店办公楼 405 单元 \\ Phone: +86-21-62489820 \\ Fax: +86-21-62489821
}


(C) 2011 The Author(s). Licensee IntechOpen. This chapter is distributed under the terms of the Creative Commons Attribution-NonCommercialShareAlike-3.0 License, which permits use, distribution and reproduction for non-commercial purposes, provided the original is properly cited and derivative works building on this content are distributed under the same license. 